\title{
Color-tunable and high quantum-yield luminescence from a biomolecule-inspired single species emitter of white light
}

Fatmah M. Ebrahim, ${ }^{1}$ Maria Fumanal, ${ }^{1,4}$ Andrzej Gtadysiak, ${ }^{1}$ Özge Kadioglu, ${ }^{1}$ Kevin Maik Jablonka, ${ }^{1}$ Daniele Ongari, ${ }^{1}$ Amber Mace,${ }^{1}$ Serhii Shyshkanov, ${ }^{1,2}$ Seryio Saris,${ }^{3}$ Christopher Patrick Ireland, ${ }^{1}$ Paul J. Dyson, ${ }^{2}$ Kyriakos C. Stylianou ${ }^{1}$ and Berend Smit ${ }^{1}$

${ }^{1}$ Laboratory of Molecular Simulation (LSMO), Institut des Sciences et Ingenierie Chimiques (ISIC), École Polytechnique Fédérale de Lausanne (EPFL); Sion, VS, Switzerland

${ }^{2}$ Institut des Sciences et Ingenierie Chimiques (ISIC), Ecole Polytechnique Fédérale de Lausanne (EPFL); CH-1015 Lausanne, Switzerland

${ }^{3}$ Laboratory of Nanochemistry of Energy (LNCE) Institute des Sciences et Ingenierie Chimiques, École Polytechnique Fédérale de Lausanne (EPFL); Sion, VS, Switzerland

${ }^{4}$ IBM Research Zurich, Säumerstrasse 4, 8803 Rüschlikon, Switzerland

*Corresponding author. Email: berend.smit@,epfl.ch

Key words: Thin-film OLED, White light emission, Organic Molecules of Intrinsic Microporosity, Luciferin

Single-species light emitters with high photoluminescence quantum yields (PLQYs) and broadspectrum color tunability are sought-after for applications ranging from bio-imaging to artificial lighting. We explore a new strategy to design such emitters, inspired by bioluminescent fireflies and click-beetles. These organisms use a single molecular substrate, D-Luciferin $\left(\mathrm{LH}_{2}\right)$, to emit light ranging in color from green to red. By combining $\mathrm{LH}_{2}$ with metals, we synthesize new bio-analogous, color-tunable, luminescent metal complexes. The copper complex forms an organic molecule of intrinsic microporosity (OMIM), which crystallizes into a stable structure with intermolecular voids. By changing the composition of guest molecules in the voids, we can tune the emitted color. The optimum composition gives nearly perfect white light, with the highest PLQY reported for a single-species whitelight emitter. Similarities between our OMIM and the luciferase active site provide a new approach to investigating the heavily-debated mechanisms underlying in-vivo bioluminescence color variations. Moreover, as a proof of principle, we show that these materials can be used in a new type of lightemitting device (LED). The current generation of LEDs requires at least two active layers to achieve color tunability. The tunability is intrinsic in our materials, and therefore may lead to simpler device fabrication. 


\section{Introduction}

The reason why we can see fireflies and click beetles at night is that these organisms are bioluminescent. Both use the same light-emitting substrate, D-Luciferin $\left(\mathrm{LH}_{2}\right)$, which is oxidized in the active site of largely homologous luciferase proteins during the bioluminescence reaction. And yet, fireflies emit green, and click beetles, red light. ${ }^{[1,2]}$ Several theories have been proposed to elucidate these color variations. ${ }^{[3-7]}$ Studies show that the polarity, hydrophobicity, and conformation of the luciferase protein surrounding $\mathrm{LH}_{2}$ play key roles, as they influence the emitter's chemical form, ${ }^{[4,6]}$ and the species proximate to its terminal groups. ${ }^{[8-10]}$ Most such studies rely on investigating the photochemical properties of the isolated emitter, or the emission from bioluminescent reactions in proteins engineered with point mutations. However, conclusive explanations have eluded the community, due to the multitude of contributing factors, and the dynamic nature of the bioluminescence reaction. As a result, no generally-accepted explanation for this exists thus far. ${ }^{[11,12]}$

What is known, however, is that $\mathrm{LH}_{2}$, its analogues, and derivative molecules, possess fascinating photochemical properties. Here, we take inspiration from $\mathrm{LH}_{2}$-based bioluminescent systems to develop a new class of synthetic emitters for a range of potential applications, including artificial lighting. These emitters exploit the photochemical properties of $\mathrm{LH}_{2}$ to harness both structural and microenvironment-triggered emission color tuneability. To achieve this, we use copper and zirconium ions to fuse $\mathrm{LH}_{2}$ molecules into stable complexes. The reaction of zirconium with $\mathrm{LH}_{2}$ produces a $\mathrm{Zr}$-based complex. Based on the analysis of mass spectra and DFT calculations (see Supplementary Information for structural details), this complex is an $\mathrm{OH}$-bridged dinuclear complex, with the formula $\mathrm{Zr}_{2}\left(\mathrm{LH}_{2}\right)_{2}(\mu-\mathrm{OH})_{2} \mathrm{Cl}_{4}$, which we named $\mathrm{ZrLH}_{2}$ (see Supplementary Figure S2). While amorphous in the solid phase, $\mathrm{ZrLH}_{2}$ is freely soluble in methanol, which is particularly advantageous for the formation of thin films from solution for the fabrication of light-emitting devices. 


\section{1. $\mathrm{Cu}-\mathrm{LH}_{2}$ metal complex}

The copper reaction on the other hand, results in a mixed-valence, porous, crystalline copper complex, which we named $\mathrm{Cu}_{2} \mathrm{~L}_{3}$. A detailed characterization of the crystal structure of $\mathrm{Cu}_{2} \mathrm{~L}_{3}$ revealed the presence of periodic intermolecular voids, characteristic of an emerging class of materials known as Organic Molecules of Intrinsic Microporosity (OMIMs). ${ }^{[13,14]}$ OMIMs are extrinsically porous crystalline materials, formed from molecules with bent, angular, or otherwise 'awkward' shapes, that pack together leaving intermolecular void spaces. $\mathrm{Cu}_{2} \mathrm{~L}_{3}$ forms as the result of a redox reaction between $\mathrm{D}-\mathrm{LH}_{2}$ and $\mathrm{Cu}\left(\mathrm{NO}_{3}\right)_{2} \cdot 2.5 \mathrm{H}_{2} \mathrm{O}$. When combined in an appropriate ratio at $373 \mathrm{~K}$ in a $\mathrm{H}_{2} \mathrm{O} / \mathrm{DMF} / \mathrm{EtOH}$ solution (See Supplementary methods for full synthesis details), $\mathrm{Cu}^{\mathrm{II}}$ is partially reduced to $\mathrm{Cu}^{\mathrm{I}}$, while $\mathrm{LH}_{2}$ is simultaneously oxidized to dehydroluciferin (L) (Figure 1a). The relatively insoluble complex consists of three L ligands linked together via two $\mathrm{Cu}$ ions; $\mathrm{Cu} 1$ and $\mathrm{Cu} 2$, in the $\mathrm{Cu}^{\mathrm{I}}$ and $\mathrm{Cu}^{\mathrm{II}}$ oxidation states respectively (Figure 1b). The $6{ }^{\prime}-\mathrm{OH}$ hydroxyl terminals of the ligands, with their ground-state $\mathrm{pKa}$ of $\sim 8,{ }^{[15]}$ remain protonated during synthesis and do not take part in coordination to the $\mathrm{Cu}$ ions.

Figure 1c shows the inefficient but regular packing of $\mathrm{Cu}_{2} \mathrm{~L}_{3}$, characteristic of porous, crystalline OMIMs. The void spaces of $\mathrm{Cu}_{2} \mathrm{~L}_{3}$, account for $13.1 \%$ of the unit-cell volume, and manifest as 1D channels that extend along the $c$ axis (Figure 1c, inset). X-ray photo-electron spectroscopy (XPS, Figure 1d and Figure S5) analysis confirms the presence of both $\mathrm{Cu}^{\mathrm{II}}$ and $\mathrm{Cu}^{\mathrm{I}}$ in the complex, in a $1: 1$ ratio. 
a

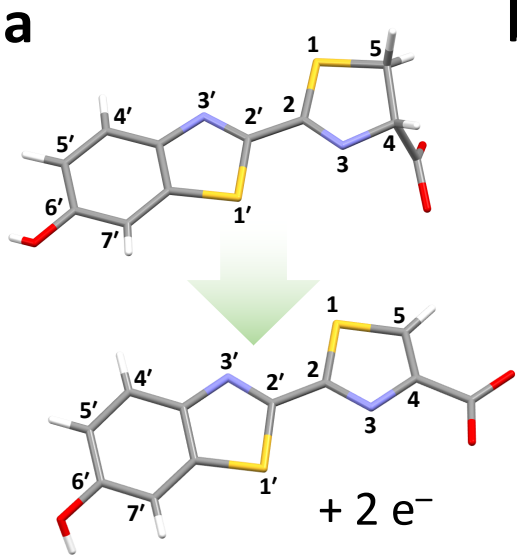

b

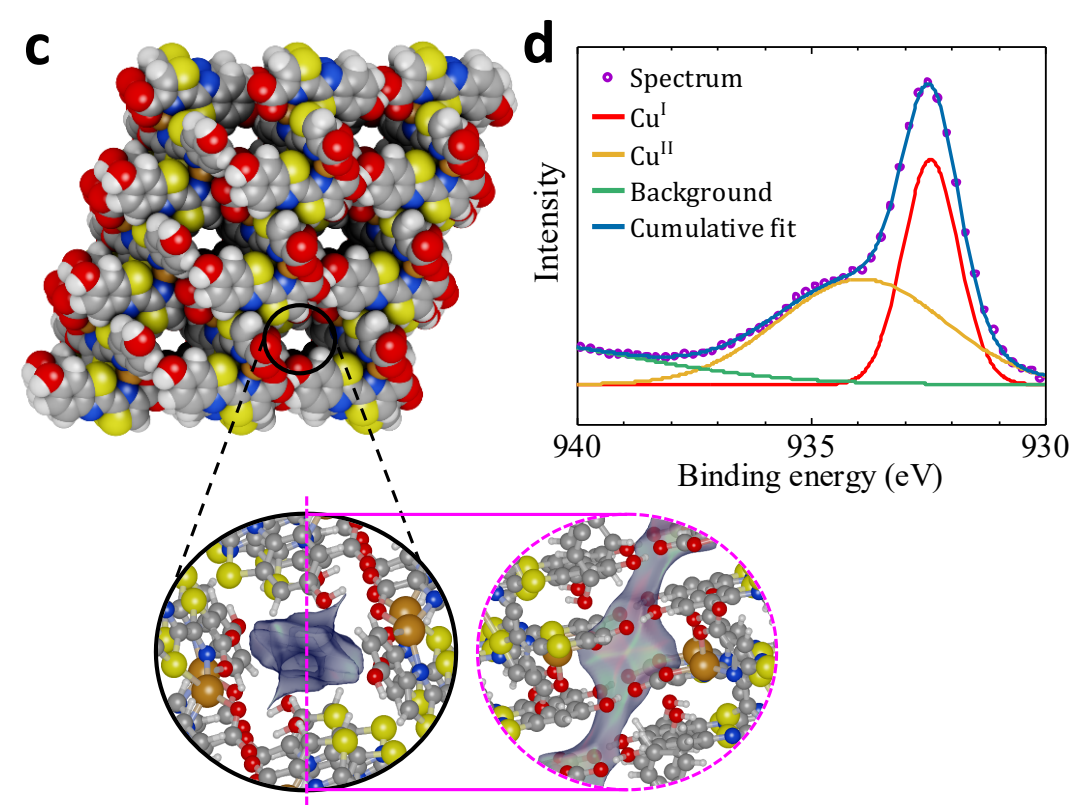

Figure 1: The structure of $\mathbf{C u}_{2} \mathbf{L}_{3}$. a Chemical transformation of luciferin ( $\mathrm{LH}_{2}$, top) into dehydroluciferin ( $\mathbf{L}$, bottom) by means of an oxidizing agent, $\mathrm{Cu}^{\mathrm{II}}$. b Asymmetric unit of $\mathrm{Cu}_{2} \mathrm{~L}_{3}$ consisting of three $\mathbf{L}$ units bridged by two $\mathrm{Cu}$ ions. c Spacefill model of $\mathrm{Cu}_{2} \mathrm{~L}_{3}$ shows $1 \mathrm{D}$ channels in the $c$-axis direction; inset: Views of internal surfaces of the channels in the crystal highlight the accessibility of ligand terminal groups. $\mathbf{d ~ C u}$ $2 \mathrm{p}$ XPS spectrum of as-synthesized $\mathrm{Cu}_{2} \mathrm{~L}_{3}$. Atom color scheme: $\mathrm{C}=$ grey, $\mathrm{H}=$ white, $\mathrm{O}=$ red, $\mathrm{N}=\mathrm{blue}, \mathrm{S}=$ yellow, $\mathrm{Cu}=$ orange.

\section{Biomimetic optical properties of $\mathrm{LH}_{2}$-based metal complexes}

The optical properties of $\mathrm{Cu}_{2} \mathrm{~L}_{3}$ are influenced by its structural aspects. Calculated and experimentally measured absorption and emission spectra of $\mathrm{Cu}_{2} \mathrm{~L}_{3}$ are shown in Figure 2a and $\mathbf{b}$ respectively. The UV-visible absorption spectrum of $\mathrm{Cu}_{2} \mathrm{~L}_{3}$ follows a similar profile to that of the free ligand $\mathrm{L}$, with a narrow absorption band at $340 \mathrm{~nm}$ corresponding to the sum of local $\pi-\pi *$ transitions in each of the three ligands, L1, L2, and L3 (Labels indicated in Figure S4). Both computed and measured spectra show that the absorption peak of $\mathrm{Cu}_{2} \mathrm{~L}_{3}$ is red-shifted 
with respect to that of the isolated ligand. When excited at $350 \mathrm{~nm}$, as-synthesized crystals of $\mathrm{Cu}_{2} \mathrm{~L}_{3}$ show a broad PL spectrum consisting of two distinct contributions; a blue peak centered at $430 \mathrm{~nm}$, and a green-yellow $550 \mathrm{~nm}$ peak. Since the $\mathrm{UV}$-visible absorption of $\mathrm{Cu}_{2} \mathrm{~L}_{3}$ is ligandcentered, these two emission peaks are attributed to the neutral and anionic forms of the complexed L ligands, respectively. The ligand precursor, D- $\mathrm{LH}_{2}$ (and many of its derivative molecules) is a strong photoacid. ${ }^{[16]}$ Photoexcitation of the molecule therefore lowers the pKa of its $6^{\prime}-\mathrm{OH}$ terminal group from $\sim 8$ to $\sim-0.5,{ }^{[15]}$ allowing proximate water molecules deprotonate them via fast excited-state intermolecular proton transfer (ESPT).
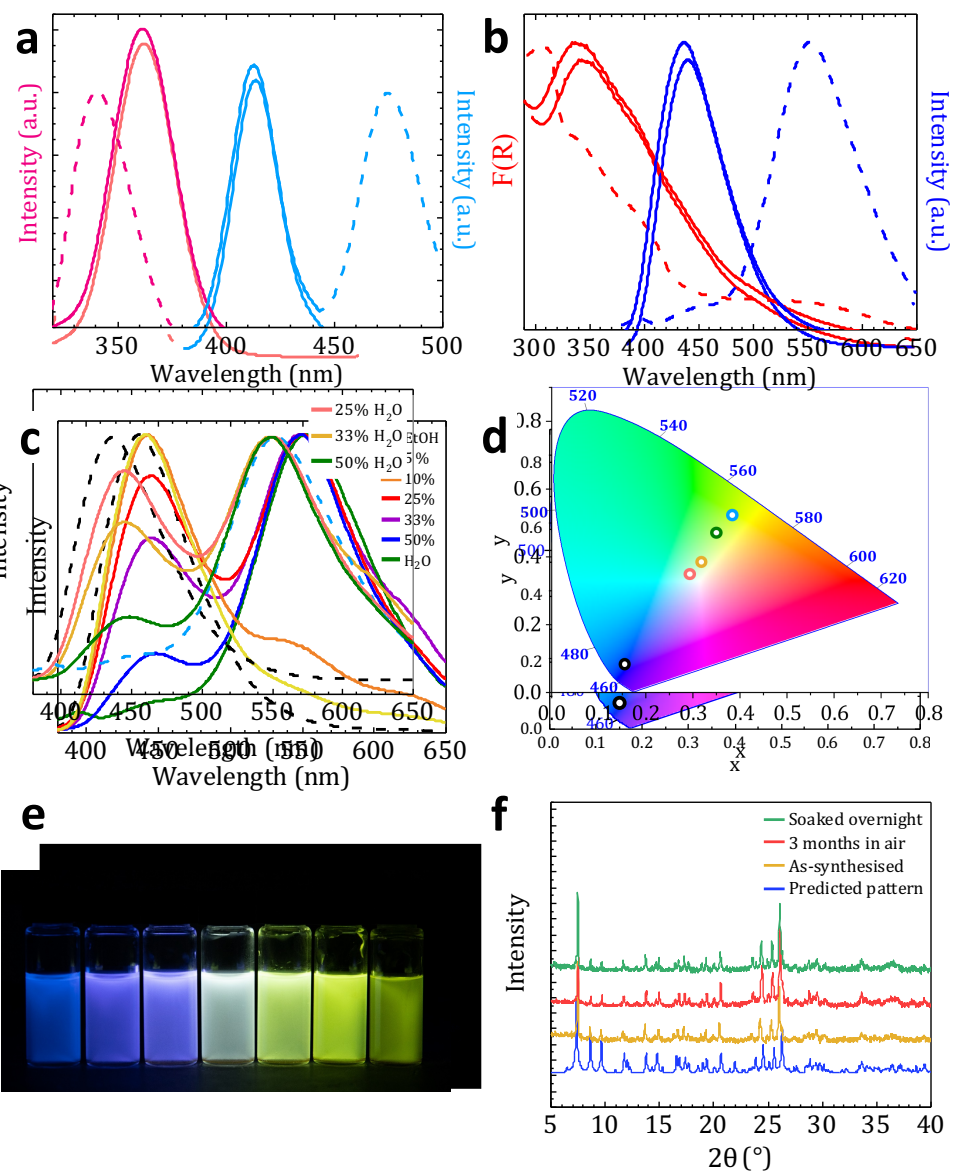

Figure 2: Optical properties of $\mathbf{C u}_{2} \mathbf{L}_{3}$. Calculated, a, and experimentally measured, b, UV-vis absorption (via diffuse reflectance) and photoluminescence (PL) emission spectra of $\mathrm{Cu}_{2} \mathrm{~L}_{3}$. Solid red lines: absorption of $\mathrm{Cu}_{2} \mathrm{~L}_{3}$; dashed red lines: absorption of free ligand $\mathbf{L}$; Solid blue lines: PL emission of neutral $\mathrm{Cu}_{2} \mathrm{~L}_{3}$; dashed blue lines: PL emission of fully deprotonated $\left(6-\mathrm{O}^{-}\right) \mathrm{Cu}_{2} \mathrm{~L}_{3}$. c Dependence of PL spectrum (normalized to the $550 \mathrm{~nm}$ peak) on the concentration of $\mathrm{H}_{2} \mathrm{O}$ in the pores of $\mathrm{Cu}_{2} \mathrm{~L}_{3}$, and $\mathbf{d}$ Corresponding emission colors. Black and blue circles/dashed lines correspond to signature 6-OH and 6-O- spectra seen in pure ethanol and pure water, respectively. CIE coordinates of $\mathrm{Cu}_{2} \mathrm{~L}_{3}$ synthesized in $25 \% \mathrm{H}_{2} \mathrm{O}$ (red circle) are $(0.29,0.33)$. e Photograph of $\mathrm{Cu}_{2} \mathrm{~L}_{3}$ crystals suspended in solvent mixtures with varying amounts of water, from the left, 0,5 , $15,25,50,75$, and $100 \%$. f stability of $\mathrm{Cu}_{2} \mathrm{~L}_{3}$ in air and in aqueous solutions is demonstrated via PXRD patterns of the material as-synthesized, after three months in open air, and after soaking overnight in an aqueous ethanol solution. 
Typically, neutral $\mathrm{LH}_{2}$-like molecules emit in the blue region, and deprotonation of the $6^{\prime}-\mathrm{OH}$ group, which results in the anionic phenolate form of the molecule, lowers the emission energy, resulting in a characteristic $100 \mathrm{~nm}$ redshift. ${ }^{[8]}$ Since the $\mathrm{Cu}_{2} \mathrm{~L}_{3}$ complex is charge-neutral, the $550 \mathrm{~nm} 6^{\prime}-\mathrm{O}^{-}$peak in the experimentally measured emission spectrum of as-synthesized crystals is attributed to the void-facing position of its $6^{\prime}-\mathrm{OH}$ terminals, which are easily deprotonated by water. While $\mathrm{Cu}_{2} \mathrm{~L}_{3}$ crystals suspended in pure water exhibit only the deprotonated $6^{\prime}-\mathrm{O}^{-}$peak at $550 \mathrm{~nm}$ (Figure 2b, dashed blue line), crystals suspended in nonaqueous solvents exhibit only the $430 \mathrm{~nm} 6^{\prime}-\mathrm{OH}$ peak characteristic of the neutral ligand (Figure 2b, solid blue line). This assignment of the optical absorption and emission peaks in $\mathrm{Cu}_{2} \mathrm{~L}_{3}$ was confirmed by density functional theory (DFT) calculations of the molecular orbitals associated with photoexcited transitions (Figure S9 and Figure S10).

\section{Color tunability of $\mathrm{LH}_{2}$-based metal complexes}

Since changes in the protonation state are influenced by the concentration of water molecules in the voids, we expect to use this mechanism to fine-tune the emission color of $\mathrm{Cu}_{2} \mathrm{~L}_{3}$, for example by changing the ethanol-water composition. Indeed, Figure $2 \mathrm{c}$ shows how the relative intensity of the two characteristic peaks in the emission spectrum can be tuned by changing the composition of the solvent. We observe that as the ratio of water is increased, the emission coordinates of the crystals follow the white region of the International Commission on Illumination (CIE) map from cool to warm (Figure 2d and e), narrowly crossing the coordinates for ideal white light. The change in color emitted from $\mathrm{Cu}_{2} \mathrm{~L}_{3}$ as water is added to a suspension of the complex in ethanol can be seen in Supplementary Movie S1. The emission of $\mathrm{Cu}_{2} \mathrm{~L}_{3}$ in $25 \%$ water is significantly broad $(\mathrm{FWHM}=182.1 \mathrm{~nm})$, and consists of the 450 and $550 \mathrm{~nm}$ peaks in a $0.75: 1.00$ intensity ratio (Figure $2 \mathrm{c}$, red line). This corresponds to nearly pure-white CIE coordinates of $(0.29,0.33)$ (Figure $2 \mathrm{~d}$, red circle). The PLQY is $57 \%$; amongst the highest reported for a single-species white light emitter, and to the best of our knowledge, the highest 
quantum yield of an emitter closest to the equal energy point of the CIE map. ${ }^{[17]}$ We attribute this to rigidity of the complex, due to the ligand $\mathrm{C} 2-\mathrm{C} 2$ ', $\mathrm{OH}$, and $\mathrm{COOH}$ bonds being locked in position by the $\mathrm{Cu}$ centers. ${ }^{[18]}$ Often the performance of an emitter is seen as a compromise between tunability and quantum yield. In our biologically-inspired complex, we have found a way to have both. Stability of the complex in air and water is demonstrated via PXRD measurements of the complex after three months in air, and after soaking in a $\mathrm{H}_{2} \mathrm{O}: \mathrm{EtOH}$ (0.25:0.75) mixture overnight (Figure 2f). Using DFT calculations, we also identified how $\mathrm{LH}_{2}-$ based modified ligands ${ }^{[19,20]}$ could form OMIM-like, complexes, similar to $\mathrm{Cu}_{2} \mathrm{~L}_{3}$, with even more extensive spectral tunability (Figure S11).

To gain insights into the interplay between water and ethanol molecules in the voids of $\mathrm{Cu}_{2} \mathrm{~L}_{3}$, we carried out Grand Canonical Monte Carlo (GCMC) and NTV Monte Carlo simulations for different solvent concentrations. As seen in Figure 3a-f, one of the preferential adsorption sites of water (site 1) lies next to the 6'-OH groups. Ethanol molecules, however, show a stronger affinity to this particular site (Figure S12 and Figure S13), and displace the water molecules, making it increasingly difficult for the $6^{\prime}-\mathrm{OH}$ to deprotonate when ethanol is present. 

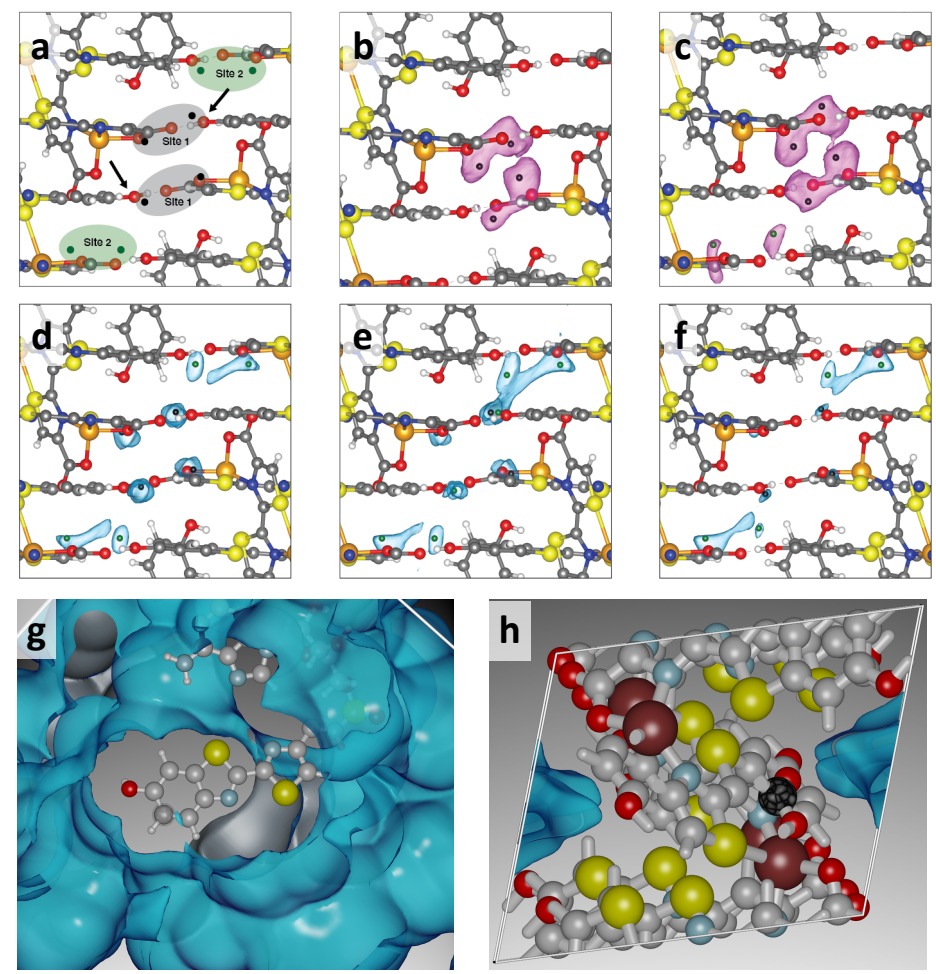

Figure 3: Bioanalogous solvent behaviour in $\mathbf{C u}_{2} \mathbf{L}_{3}$ pores. a-f Solvent adsorption probability density plots viewed from $\mathrm{x}$-direction computed in the $3 \times 3 \times 2$ supercell of DFT optimized $\mathrm{Cu}_{2} \mathrm{~L}_{3}$ at $298.15 \mathrm{~K}$ and 0.02 bar. Blue and pink clouds represent the free energy grid corresponding to $\mathrm{O}$ atoms in $\mathrm{H}_{2} \mathrm{O}$ and in EtOH, with the $\mathrm{H}_{2} \mathrm{O}$ compositions of $\mathbf{a}, \mathbf{d} 100 \% \mathbf{b}$, e $50 \%$ and $\mathbf{c}, \mathbf{f} 25 \%$. Black and green dots correspond to minimum energy basins for $\mathrm{H}_{2} \mathrm{O}$ adsorption site 1 and 2, respectively. Black arrows in a indicate the $\mathrm{O}$ atoms associated with those $-\mathrm{OH}$ terminals that are subject to deprotonation. $\mathbf{g}, \mathbf{h}$, Water adsorption surfaces of $\mathrm{Cu}_{2} \mathrm{~L}_{3}$ and the ATPbound molecule in the L. cruciata protein pocket. For visual clarity, we omit the amino acids that form the protein but they are considered for the calculation of the adsorption surface.

Interestingly, the packing of the ligand units in $\mathrm{Cu}_{2} \mathrm{~L}_{3}$ bears a remarkable resemblance to that of $\mathrm{LH}_{2}$ in the luciferase active site of the L. cruciata firefly ${ }^{[6,8]}$ (Figure $3 g$ and h). In particular, analysis of the water adsorption surface within $\mathrm{Cu}_{2} \mathrm{~L}_{3}$ voids show that in both structures, the $6^{\prime}-$ $\mathrm{OH}$ can, from all hydrogen bonding active functional groups, most strongly interact with water (full details in Supplementary Information). Based on similarity analyses between the structure of our compound and the Oxy- $\mathrm{LH}_{2}$ molecule embedded in the luciferase protein scaffold (PDB 2D1T), the maximum distance of the oxygen of the water molecule to oxygen the phenolic $\mathrm{OH}$ group is $3.3 \AA$ in our simulations, which is close to the distances of $2.73 \AA$ and $3.3 \AA$ that are found in the protein. The challenge in studying the color-tuning mechanism observed in nature has been to disentangle the different factors contributing to it. In our material, we locked the 
solvent-emitter interactions into a stable synthetic binding pocket of $\mathrm{Cu}_{2} \mathrm{~L}_{3}$, and were thus able to confirm the drastic effect of changes in solvent composition on the emission color, while all other variables are fixed. By introducing systematic modifications to the ligand, we can mimic some of the point mutations introduced in luciferase proteins and systematically study their behavior.

\section{Bioluminescence-inspired proof-of-concept thin-film LEDs}

While the molecular mechanism that determines the color of light emitted by bioluminescent organisms remains under debate, the bioluminescence reaction process is well understood. In this reaction, the enzyme, luciferase, converts the molecular substrate, $\mathrm{LH}_{2}$, into an adenosine monophosphate (AMP)-bound intermediate. ${ }^{[21-23]}$ Following oxidation by molecular oxygen, a basic residue in the luciferase pocket then promotes the abstraction of a proton from the C-4 carbon of the intermediate. Subsequent loss of $\mathrm{CO}_{2}$ results in electronically excited $\mathrm{OxyLH}_{2}$ that decays to produce light. In this way, nature succeeds in perfectly balancing the bipolar electron and hole injection into a luminescent molecular substrate to generate light, almost like a biological LED. Our detailed characterization of the structure of $\mathrm{Cu}_{2} \mathrm{~L}_{3}$ facilitated the use of DFT to calculate the energetic positions of its Highest Occupied and Lowest Unoccupied Molecular Orbitals (HOMO and LUMO, respectively), which are crucial characteristics in designing the architecture of an LED. Our calculations, described in detail in the Supplementary Information, suggest that upon injecting charge carriers, the first reduction and oxidation of $\mathrm{Cu}_{2} \mathrm{~L}_{3}$ takes place in the $\mathrm{Cu} 2$ and $\mathrm{Cu} 1$ copper centers. This is unsurprising given the low redox

potential of $\mathrm{Cu}$ ions, ${ }^{[24,25]}$ however it means that careful design of device architecture is required to balance the electron- and hole-injection rates and obtain electroluminescence from $\mathrm{Cu}_{2} \mathrm{~L}_{3}$. 

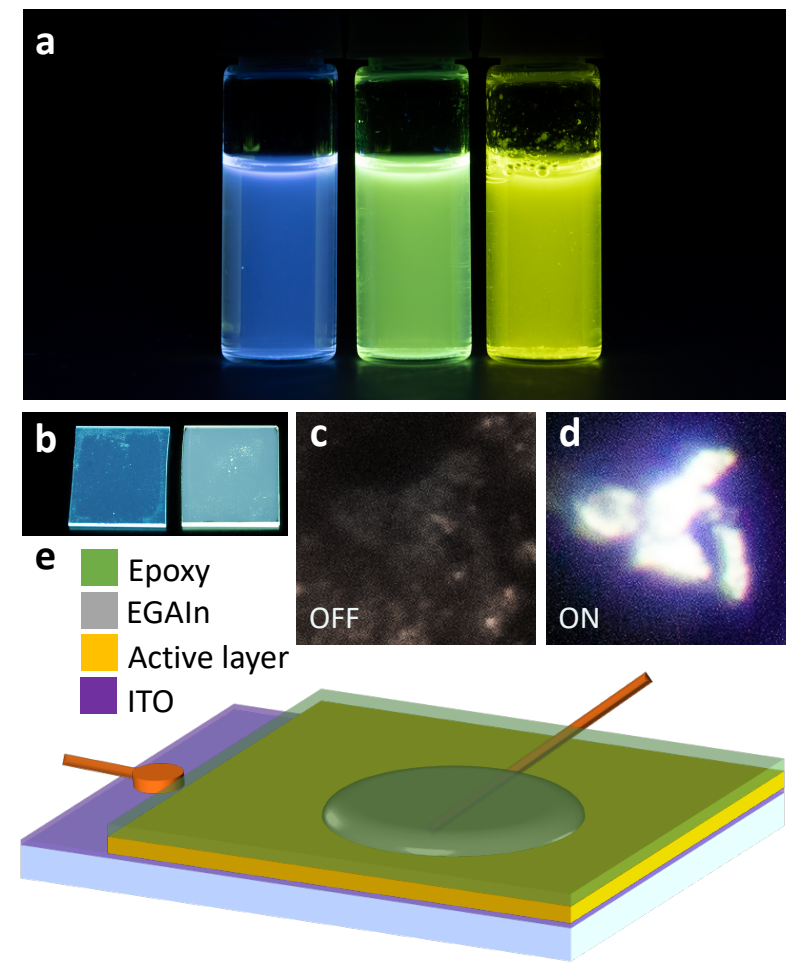

Figure 4: Simple tunable device from $\mathrm{ZrLH}_{2}$ complex. a Photograph of $\mathrm{ZrLH}_{2}$ dissolved in methanol-water mixtures with varying amounts of water, from the left, 0, 25, and 100\% by volume. b ZrLH2@PVP layers without (left) and with (right) the ionic liquid EAN showing colour tunability in dried substrates. c, d photographs of a working device made with $\mathrm{ZrLH}_{2}$ when switched off $(\mathbf{c})$ and on (d). e schematic of the simple working device made with $\mathrm{ZrLH}_{2}$. ITO = indium-tin oxide, Active layer= $\mathrm{ZrLH}_{2} @ \mathrm{PVP}, \mathrm{EGaIn}=$ galliumindium eutectic.

Since $\mathrm{Zr}$ is known to have a higher redox potential, ${ }^{[26,27]}$ the $\mathrm{Zr}$ analogue of $\mathrm{Cu}_{2} \mathrm{~L}_{3}$ was used to demonstrate the applicability of our strategy towards tunable emitters for LEDs. Also, relying on water to deprotonate the $6^{\prime}-\mathrm{OH}$ groups may be complicated from a device point of view, as it requires careful sealing to avoid evaporation. Instead, low-vapor pressure ionic liquids (ILs), which are typically used as electrolytes in batteries or fuel cells, can substitute water. Since ILs can be relatively bulky, it is preferable to have a freely soluble complex rather than a porous crystal in the active layer of a device. The IL ethylammoniun nitrate (EAN) was selected based on its chemical similarities to water, and is capable of deprotonating the $6^{\prime}-\mathrm{OH}$ groups of the ligand. This indicates that the $\mathrm{OH}$ groups are accessible to the IL, which strongly suggests a similar color tuning mechanism. 
Indeed, Figure $4 \mathbf{b}$ shows that adding EAN to a dry film of $\mathrm{ZrLH}_{2}$ gives rise to a color tunability similar to that in $\mathrm{Cu}_{2} \mathrm{~L}_{3}$. Another advantage of having a freely soluble is much easier processability. By dissolving $\mathrm{ZrLH}_{2}$ into a polyvinylpyrrolidone (PVP) host, we were able to make a simple single-layer LED entirely from solution. To do this, the $\mathrm{ZrLH}_{2} @ \mathrm{PVP}$ mixture was drop-cast onto indium-tin-oxide (ITO)-coated glass substrates and left to dry in open air before depositing a gallium-indium cathode. Similar to its copper-based counterpart, $\mathrm{ZrLH}_{2}$ exhibits ligand-centered optical properties, including emission color tunability that can be exploited by changing the water content surrounding its $6^{\prime}-\mathrm{OH}$ terminals (Figure 4a). Dropcast layers of $\mathrm{ZrLH}_{2}$ in PVA on ITO form a simple working LED, processed entirely from solution, that emits a cold white light at an applied voltage of 5V (Figure 4c-e).

Remarkably, this rudimentary working device was fabricated and operated in open air, without the need for any charge-injection or -blocking layers. The simple, low-cost synthesis, singlespecies tunability, high quantum yields, and potentially straightforward implementation into working LEDs, all demonstrate the promise for a new family of $\mathrm{LH}_{2}$-based light emitters reported in this manuscript.

\section{Conclusion}

We report a novel strategy for designing high-stability, high quantum-yield, color-tunable light emitters. Taking lessons from nature, we mimic the bioluminescence of fireflies and click beetles in a series of metal complexes based on the bioluminescent molecule, luciferin $\left(\mathrm{LH}_{2}\right)$. Using a low-cost, low-temperature, water-based synthetic protocol, we obtain highly stable electroluminescent materials, whose emission colors can be tuned by varying the concentration of small-molecule ionic liquids in their immediate environment.

Our copper complex in particular, crystallizes to form a porous structure with regular voids that mimic the binding pocket surrounding naturally-occurring $\mathrm{LH}_{2}$ in bioluminescent organisms. 
These striking similarities provide a unique molecular model, through which we can gain insights into the elusive bioluminescence color-determining mechanisms that remain under debate.

Using our materials, we prepare a rudimentary proof-of-principle LED, which was fabricated in open air at room temperature, consists of only a single active layer, and exhibits a stable emission for over ten hours under a continuous applied voltage of $6 \mathrm{~V}$.

\section{Acknowledgements}

The authors thank Dr. Emad Oveisi for SEM and EDX analysis, Dr. Mounir Mensi for XPS measurements, Prof. Raffaella Buonsanti for use of instruments, Prof. Mohammad Kaja Nazeeruddin for discussion, and Dr. Giovanni Resta and Mr. Patrick Favre for photographs and videos. The authors acknowledge the National Center of Competence in Research (NCCR), Materials' Revolution: Computational Design and Discovery of Novel Materials (MARVEL), Swiss National Science Foundation (SNF) under the Ambizione Energy Grant (n. PZENP2_166888), and the European Research Council (ERC) Advanced Grant (Grant Agreement No. 666983, MaGic) for funding.

\section{References}

1. H. Fraga, Firefly luminescence: A historical perspective and recent developments. Photochem. Photobiol. Sci. 7, 146-158 (2008).

2. D. T. Amaral, G. Oliveira, J. R. Silva, V. R. Viviani, A new orange emitting luciferase from the Southern-Amazon Pyrophorus angustus (Coleoptera: Elateridae) click-beetle: structure and bioluminescence color relationship, evolutional and ecological considerations. Photochem. Photobiol. Sci. 15, 1148-1154 (2016).

3. E. H. White, E. Rapaport, T. A. Hopkins, H. H. Seliger, Chemi- and bioluminescence of firefly luciferin. J. Am. Chem. Soc. 91, 2178-2180 (1969).

4. B. R. Branchini, T. L. Southworth, M. H. Murtiashaw, R. A. Magyar, S. A. Gonzalez, M. C. Ruggiero, J. G. Stroh, An Alternative Mechanism of Bioluminescence Color Determination in Firefly Luciferase. Biochemistry. 43, 7255-7262 (2004).

5. N. N. Ugarova, L. G. Maloshenok, I. V. Uporov, M. I. Koksharov, Bioluminescence Spectra of Native and Mutant Firefly Luciferases as a Function of pH. Biochemistry (Moscow). 70, 1262-1267 (2005).

6. T. Nakatsu, S. Ichiyama, J. Hiratake, A. Saldanha, N. Kobashi, K. Sakata, H. Kato, Structural basis for the spectral difference in luciferase bioluminescence. Nature. $\mathbf{4 4 0}$, 372-376 (2006). 
7. Y. Ando, K. Niwa, N. Yamada, T. Enomoto, T. Irie, H. Kubota, Y. Ohmiya, H. Akiyama, Firefly bioluminescence quantum yield and colour change by $\mathrm{pH}$-sensitive green emission. Nature Photonics. 2, 44-47 (2008).

8. P. Naumov, Y. Ozawa, K. Ohkubo, S. Fukuzumi, Structure and Spectroscopy of Oxyluciferin, the Light Emitter of the Firefly Bioluminescence. J. Am. Chem. Soc. 131, 11590-11605 (2009).

9. V. R. Viviani, G. V. M. Gabriel, V. R. Bevilaqua, A. F. Simões, T. Hirano, P. S. Lopesde-Oliveira, The proton and metal binding sites responsible for the $\mathrm{pH}$-dependent greenred bioluminescence color tuning in firefly luciferases. Scientific Reports. 8, 17594 (2018).

10. M. Kheirabadi, Z. Sharafian, H. Naderi-Manesh, U. Heineman, U. Gohlke, S. Hosseinkhani, Crystal structure of native and a mutant of Lampyris turkestanicus luciferase implicate in bioluminescence color shift. Biochimica et Biophysica Acta (BBA) - Proteins and Proteomics. 1834, 2729-2735 (2013).

11. Z. M. Kaskova, A. S. Tsarkova, I. V. Yampolsky, 1001 lights: luciferins, luciferases, their mechanisms of action and applications in chemical analysis, biology and medicine. Chemical Society Reviews. 45, 6048-6077 (2016).

12. C. Carrasco-López, N. M. Lui, S. Schramm, P. Naumov, The elusive relationship between structure and colour emission in beetle luciferases. Nature Reviews Chemistry. 5, 4-20 (2021).

13. J. R. Holst, A. Trewin, A. I. Cooper, Porous organic molecules. Nature Chemistry. 2, 915-920 (2010).

14. Porous Molecular Solids and Liquids | ACS Central Science, (available at https://pubs.acs.org/doi/10.1021/acscentsci.7b00146).

15. Y. Erez, D. Huppert, Excited-State Intermolecular Proton Transfer of the Firefly's Chromophore d-Luciferin. J. Phys. Chem. A. 114, 8075-8082 (2010).

16. L. P. da Silva, R. Simkovitch, D. Huppert, J. C. G. E. da Silva, Oxyluciferin Photoacidity: The Missing Element for Solving the Keto-Enol Mystery? ChemPhysChem. 14, 34413446 (2013).

17. Z. Chen, C.-L. Ho, L. Wang, W.-Y. Wong, Single-Molecular White-Light Emitters and Their Potential WOLED Applications. Advanced Materials. 32, 1903269 (2020).

18. L. L. Bras, K. Chaitou, S. Aloïse, C. Adamo, A. Perrier, Aggregation-caused quenching versus crystallization induced emission in thiazolo[5,4-b]thieno[3,2-e]pyridine (TTP) derivatives: theoretical insights. Phys. Chem. Chem. Phys. 21, 46-56 (2018).

19. D. C. McCutcheon, M. A. Paley, R. C. Steinhardt, J. A. Prescher, Expedient Synthesis of Electronically Modified Luciferins for Bioluminescence Imaging. J. Am. Chem. Soc. 134, 7604-7607 (2012).

20. N. R. Conley, A. Dragulescu-Andrasi, J. Rao, W. E. Moerner, A Selenium Analogue of Firefly D-Luciferin with Red-Shifted Bioluminescence Emission. Angewandte Chemie International Edition. 51, 3350-3353 (2012). 
21. M. Deluca, in Advances in Enzymology and Related Areas of Molecular Biology (John Wiley \& Sons, Ltd, 1976;

https://onlinelibrary.wiley.com/doi/abs/10.1002/9780470122891.ch2), pp. 37-68.

22. M. DeLuca, W. D. McElroy, Kinetics of the firefly luciferase catalyzed reactions. Biochemistry. 13, 921-925 (1974).

23. N. Wada, M. Honda, H. Suzuki, Theory of D-(-)-Luciferin and Dehydroluciferin in Acidic or Basic Solution. J. Phys. Soc. Jpn. 54, 4851-4860 (1985).

24. J. D. Cope, H. U. Valle, R. S. Hall, K. M. Riley, E. Goel, S. Biswas, M. P. Hendrich, D. O. Wipf, S. L. Stokes, J. P. Emerson, Tuning the Copper(II)/Copper(I) Redox Potential for More Robust Copper-Catalyzed C-N Bond Forming Reactions. European Journal of Inorganic Chemistry. 2020, 1278-1285 (2020).

25. J. Qiu, K. Matyjaszewski, L. Thouin, C. Amatore, Cyclic voltammetric studies of copper complexes catalyzing atom transfer radical polymerization. Macromolecular Chemistry and Physics. 201, 1625-1631 (2000).

26. S. Imdadul Hossain, M. Abdul Aziz, D. Han, P. Selvam, S. Shanmugam, Fabrication of SPAEK-cerium zirconium oxide nanotube composite membrane with outstanding performance and durability for vanadium redox flow batteries. Journal of Materials Chemistry A. 6, 20205-20213 (2018).

27. J. Su, S. Yuan, T. Wang, C. Tori Lollar, J.-L. Zuo, J. Zhang, H.-C. Zhou, Zirconium metal-organic frameworks incorporating tetrathiafulvalene linkers: robust and redoxactive matrices for in situ confinement of metal nanoparticles. Chemical Science. 11, 1918-1925 (2020).

28. D. C. McCutcheon, M. A. Paley, R. C. Steinhardt, J. A. Prescher, Expedient Synthesis of Electronically Modified Luciferins for Bioluminescence Imaging. J. Am. Chem. Soc. 134, 7604-7607 (2012).

29. E. H. White, F. McCapra, G. F. Field, W. D. McElroy, THE STRUCTURE AND SYNTHESIS OF FIREFLY LUCIFERIN. J. Am. Chem. Soc. 83, 2402-2403 (1961).

30. P. Ciuffreda, S. Casati, G. Meroni, E. Santaniello, A new synthesis of dehydroluciferin [2(6'-hydroxy-2'-benzothiazolyl)-thiazole-4-carboxylic acid] from 1,4-benzoquinone.

Tetrahedron. 69, 5893-5897 (2013).

31. Global Spectral Deconvolution Based on Non-Negative Matrix Factorization in GC $\times$ GC-HRTOFMS | Analytical Chemistry, (available at https://pubs.acs.org/doi/full/10.1021/ac5038544).

32. L. Patiny, M. Zasso, D. Kostro, A. Bernal, A. M. Castillo, A. Bolaños, M. A. Asencio, N. Pellet, M. Todd, N. Schloerer, S. Kuhn, E. Holmes, S. Javor, J. Wist, The C6H6 NMR repository: An integral solution to control the flow of your data from the magnet to the public. Magnetic Resonance in Chemistry. 56, 520-528 (2018).

33. F. Lu, R. A. Zarkesh, A. F. Heyduk, A Redox-Active Ligand as a Reservoir for Protons and Electrons: O2 Reduction at Zirconium(IV). European Journal of Inorganic Chemistry. 2012, 467-470 (2012). 
34. Summary: B3LYP proper reference, (available at http://www.ccl.net/chemistry/resources/messages/2002/05/22.008-dir/).

35. Basis Sets | Gaussian.com, (available at https://gaussian.com/basissets/).

36. Citation | Gaussian.com, (available at https://gaussian.com/citation/).

37. G. M. Sheldrick, SHELXT - Integrated space-group and crystal-structure determination. Acta Cryst A. 71, 3-8 (2015).

38. G. M. Sheldrick, Crystal structure refinement with SHELXL. Acta Cryst C. 71, 3-8 (2015).

39. O. V. Dolomanov, L. J. Bourhis, R. J. Gildea, J. a. K. Howard, H. Puschmann, OLEX2: a complete structure solution, refinement and analysis program. J Appl Cryst. 42, 339-341 (2009).

40. P. van der Sluis, A. L. Spek, BYPASS: an effective method for the refinement of crystal structures containing disordered solvent regions. Acta Cryst A. 46, 194-201 (1990).

41. (IUCr) PLATON SQUEEZE: a tool for the calculation of the disordered solvent contribution to the calculated structure factors, (available at https://onlinelibrary.wiley.com/iucr/doi/10.1107/S2053229614024929).

42. C. F. Macrae, I. J. Bruno, J. A. Chisholm, P. R. Edgington, P. McCabe, E. Pidcock, L. Rodriguez-Monge, R. Taylor, J. van de Streek, P. A. Wood, Mercury CSD 2.0 - new features for the visualization and investigation of crystal structures. J Appl Cryst. 41, 466470 (2008).

43. Conquering Aggregation-Induced Solid-State Luminescence Quenching of Carbon Dots through a Carbon Dots-Triggered Silica Gelation Process | Chemistry of Materials, (available at https://pubs.acs.org/doi/10.1021/acs.chemmater.6b05375).

44. D. G. Congrave, B. H. Drummond, V. Gray, A. D. Bond, A. Rao, R. H. Friend, H. Bronstein, Suppressing aggregation induced quenching in anthracene based conjugated polymers. Polym. Chem. (2021), doi:10.1039/D1PY00118C.

45. W. Kohn, L. J. Sham, Self-Consistent Equations Including Exchange and Correlation Effects. Phys. Rev. 140, A1133-A1138 (1965).

46. C. Adamo, D. Jacquemin, The calculations of excited-state properties with TimeDependent Density Functional Theory. Chem. Soc. Rev. 42, 845-856 (2013).

47. C. Adamo, G. E. Scuseria, V. Barone, Accurate excitation energies from time-dependent density functional theory: Assessing the PBE0 model. J. Chem. Phys. 111, 2889-2899 (1999).

48. K. Raghavachari, G. W. Trucks, Highly correlated systems. Excitation energies of first row transition metals Sc-Cu. The Journal of Chemical Physics. 91, 1062 (1998).

49. A. D. McLean, G. S. Chandler, Contracted Gaussian basis sets for molecular calculations. I. Second row atoms, Z=11-18. J. Chem. Phys. 72, 5639-5648 (1980). 
50. V. Barone, M. Cossi, Quantum Calculation of Molecular Energies and Energy Gradients in Solution by a Conductor Solvent Model. J. Phys. Chem. A. 102, 1995-2001 (1998).

51. M. Cossi, N. Rega, G. Scalmani, V. Barone, Energies, structures, and electronic properties of molecules in solution with the C-PCM solvation model. Journal of Computational Chemistry. 24, 669-681 (2003).

52. Gaussian 09 Citation | Gaussian.com, (available at https://gaussian.com/g09citation/).

53. UFF, a full periodic table force field for molecular mechanics and molecular dynamics simulations $\mid$ Journal of the American Chemical Society, (available at https://pubs.acs.org/doi/abs/10.1021/ja00051a040).

54. Applicability of Tail Corrections in the Molecular Simulations of Porous Materials | Journal of Chemical Theory and Computation, (available at https://pubs.acs.org/doi/full/10.1021/acs.jctc.9b00586).

55. J. L. F. Abascal, C. Vega, A general purpose model for the condensed phases of water: TIP4P/2005. J. Chem. Phys. 123, 234505 (2005).

56. Monte Carlo Calculations for Alcohols and Their Mixtures with Alkanes. Transferable Potentials for Phase Equilibria. 5. United-Atom Description of Primary, Secondary, and Tertiary Alcohols $\mid$ The Journal of Physical Chemistry B, (available at https://pubs.acs.org/doi/abs/10.1021/jp003882x).

57. D. Dubbeldam, S. Calero, T. J. H. Vlugt, iRASPA: GPU-accelerated visualization software for materials scientists. Molecular Simulation. 44, 653-676 (2018).

58. S. Iwano, R. Obata, C. Miura, M. Kiyama, K. Hama, M. Nakamura, Y. Amano, S. Kojima, T. Hirano, S. Maki, H. Niwa, Development of simple firefly luciferin analogs emitting blue, green, red, and near-infrared biological window light. Tetrahedron. 69, 3847-3856 (2013). 


\section{Supporting Information}

\section{Color-tunable and high quantum-yield luminescence from a biomolecule-inspired single species emitter of white light}

Fatmah M. Ebrahim, ${ }^{1}$ Maria Fumanal, ${ }^{1,4}$ Andrzej Gładysiak, ${ }^{1}$ Özge Kadioglu, ${ }^{1}$ Kevin Maik Jablonka, ${ }^{1}$ Daniele Ongari, ${ }^{1}$ Amber Mace, ${ }^{1}$ Serhii Shyshkanov, ${ }^{1,2}$ Seryio Saris, ${ }^{3}$ Christopher Patrick Ireland, ${ }^{1}$ Paul J. Dyson, ${ }^{2}$ Kyriakos C. Stylianou ${ }^{1}$ and Berend Smit ${ }^{{ }^{*}}$

\section{Materials and Methods}

Materials

All of the starting chemicals are commercially available and were used without any further purification. D-Cysteine was purchased from Fluorochem. 2-Cyano-6hydroxybenzothiazole and potassium carbonate were purchased from Acros. $\mathrm{Cu}\left(\mathrm{NO}_{3}\right)_{2} \cdot 2.5 \mathrm{H}_{2} \mathrm{O}(98 \%)$ was purchased from Alfa Aeser.

Synthesis of D-Luciferin $\left(\mathrm{LH}_{2}\right)$

D-Cysteine (1.444 g, $11.92 \mathrm{mmol})$ and 2-cyano-6-hydroxybenzothiazole (2.000 g, $11.35 \mathrm{mmol}$ ) were suspended in $\mathrm{MeOH}-\mathrm{H}_{2} \mathrm{O} 2: 1$ mixture $(80 \mathrm{~mL})$ in a $100 \mathrm{~mL}$ Schlenk flask. After addition of potassium carbonate $(1.6448 \mathrm{~g}, 11.92 \mathrm{mmol})$ to the mixture the color changed to bright yellow-green and the resulting solution was stirred under $\mathrm{N}_{2}$ overnight. Methanol was removed in vacuo and the remaining aqueous solution was acidified with $1 \mathrm{M}$ $\mathrm{HCl}$ solution to maximize the amount of precipitate, which was extracted with EtOAc $(3 \times 50 \mathrm{~mL})$. The combined organic phase was dried over $\mathrm{Na}_{2} \mathrm{SO}_{4}$ and evaporated to afford Dluciferin $\left(\mathrm{LH}_{2}\right)$ as a pale yellow solid $(2.630 \mathrm{~g}, 96 \%) .{ }^{1} \mathrm{H}$ NMR $\left(400 \mathrm{MHz}\right.$, Methanol- $\left.d_{4}\right) \delta$ $7.89(\mathrm{~d}, J=8.9 \mathrm{~Hz}, 1 \mathrm{H}), 7.33(\mathrm{~d}, J=2.4 \mathrm{~Hz}, 1 \mathrm{H}), 7.06(\mathrm{dd}, J=8.9,2.4 \mathrm{~Hz}, 1 \mathrm{H}), 5.38(\mathrm{t}, J=$ $9.1 \mathrm{~Hz}, 1 \mathrm{H}), 3.75(\mathrm{~m}, 2 \mathrm{H}) .(1){ }^{13} \mathrm{C}$ NMR $(101 \mathrm{MHz}, \mathrm{MeOD}) \delta 173.34,167.64,159.00,158.50$, $148.14,139.11,125.91,118.18,107.32,79.47,35.84 .(28){ }^{1} \mathrm{H}(400.13 \mathrm{MHz})$ and ${ }^{13} \mathrm{C}(100.62$ $\mathrm{MHz}$ ) NMR spectra were recorded on a Bruker Avance II 400 spectrometer at $298 \mathrm{~K}$.

Synthesis of dehydroluciferin $(29,30)$

D-luciferin (115 mg, $0.41 \mathrm{mmol})$ was dissolved in $250 \mathrm{~mL}$ of aqueous $\mathrm{NaOH}(1 \mathrm{M})$ and the resulting solution was heated to $100^{\circ} \mathrm{C}$. Air was bubbled through the solution for $6 \mathrm{~h}$ with vigorous stirring, then the reaction mixture was cooled, acidified with $1 \mathrm{M} \mathrm{HCl}$ and extracted with EtOAc $(3 \times 25 \mathrm{~mL})$. The product was subjected to column chromatography (DCM-MeOH, 4:1), resulting in dark violet solid (47 mg, 41\%). ${ }^{1} \mathrm{H}$ NMR (400 MHz, DMSOd $\left.{ }_{6}\right) 10.17(\mathrm{~s}, 1 \mathrm{H}), 8.67(\mathrm{~s}, 1 \mathrm{H}), 7.91(\mathrm{~d}, \mathrm{~J}=8.8 \mathrm{~Hz}, 1 \mathrm{H}), 7.46(\mathrm{~d}, \mathrm{~J}=2.4 \mathrm{~Hz}, 1 \mathrm{H}), 7.04(\mathrm{dd}, \mathrm{J}=$ 8.8, $2.4 \mathrm{~Hz}, 1 \mathrm{H}$ ). ${ }^{13} \mathrm{C}$ NMR (DMSO-d6): $\delta=162.1,161.8,157.5,157.0,148.8,146.8,137.2$, 131.6, 124.7, 117.6, 107.5. ESI MS m/z 276.9768 (calcd 276.9742 [M-H] ${ }^{-}$). 
Synthesis of the $\underline{\mathrm{Cu}}_{2} \underline{\mathrm{L}}_{3} \underline{\text { complex }}$

$\mathrm{Cu}\left(\mathrm{NO}_{3}\right)_{2} \cdot 2.5 \mathrm{H}_{2} \mathrm{O}(20 \mathrm{mg}, 0.068 \mathrm{mmol})$ and $20 \mathrm{mg}(0.071 \mathrm{mmol})$ of $\mathrm{LH}_{2}$ were introduced into borosilicate glass scintillation vials, dissolved in a DMF- $\mathrm{H}_{2} \mathrm{O}-\mathrm{EtOH}$ 3:1:1 mixture $(6 \mathrm{~mL})$, and then sealed and heated to $100^{\circ} \mathrm{C}$ for 16 hours. Reddish-brown crystals of $\mathbf{C u}_{2} \mathbf{L}_{3}$ were isolated by centrifugation with the yield of $\sim 70 \%(15 \mathrm{mg})$. The purity of the product was confirmed by elemental analysis and PXRD of the solid crystals.

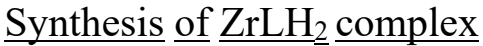

$\mathrm{ZrCl}_{4}$ and D- $\mathrm{LH}_{2}$ were combined in a 2:1 ratio and refluxed in methanol for 3 hours. The solvent was left to evaporate resulting in a low yield of the yellow solid product. 


\section{$\underline{\text { DFT }}$ optimization of $\underline{\mathrm{ZrLH}_{2}} \underline{\text { structure }}$}

Based on these findings, we manually enumerated some dinuclear zirconium complexes, also inspired by the literature (using a search in the CSD with dinuclear Zr bridged by $\mathrm{OH} / \mathrm{Cl}$ as pattern)(33), and optimized their structure using DFT (B3LYP)(34) hybrid functional with LANL2DZ basis set(35), and ultrafine integral settings in Gaussian 16(36). To estimate the stability we calculated the formation energies. We find that both a $\mathrm{OH}$ and $\mathrm{Cl}$ bridged dinuclear complex are stable, with the $\mathrm{OH}$ bridge one being slightly more stable. Based on these DFT calculations and our analysis of the mass spectra, the $\mathrm{OH}$ bridge dinuclear complex best represents the structure of $\mathrm{ZrLH}_{2}$ (see fig. S2)

\section{$\underline{\text { Single-crystal X-ray diffraction }}$}

Diffraction data were collected on a BRUKER D8 VENTURE four-circle diffractometer equipped with a MoK $\alpha$ microfocus sealed X-ray tube and a Photon 100 2D CMOS detector. The crystal structure was solved with SHELXT(37) and refined with SHELXL programs integrated within the Olex2 program suite $(38,39)$. All non-H atoms were found upon solution and refined anisotropically. Aromatic $\mathrm{H}$ atoms were introduced based on the molecular geometry with the AFIX 43 command, while those belonging to the hydroxy groups were found from the Fourier-difference maps and refined either independently (H3) or using AFIX 83 or AFIX 147 commands (H6 and H9). No additional H atoms in proximity to $\mathrm{N}$ or S atoms were found from the Fourier-difference maps. Several restraints were imposed on the atomic displacement parameters of the non-H atoms. The contribution of the disordered solvent molecules found in the structural voids to the measured structure factors was quantified using the solvent masking procedure implemented in Olex2 equivalent to PLATON SQUEEZE(4042). Structure-derived pore volume was calculated from the hypothetical solvent-free structure with the program Mercury(43) using the probe radius of $1.2 \AA$ and approx. grid spacing of $0.7 \AA$.

\section{Material characterization}

Powder X-ray diffraction (PXRD) data on all samples were collected on a Bruker D8 Advance diffractometer at ambient temperature using monochromated $\mathrm{Cu} K \alpha$ radiation $(\lambda=$ $1.5418 \AA$ ), with a $2 \theta$ step of $0.02^{\circ}$ and a $2 \theta$ range of $\sim 2$ to $70^{\circ}$. Simulated PXRD patterns were generated from the corresponding crystal structures using Mercury 3.0. X-ray photoelectron spectroscopy (XPS) was performed using a PHI 5000 Versaprobe-II instrument from Physical Electronics. Samples were deposited on an insulating double sided, vacuum compatible, taped, and charge neutralization was applied during the XPS measurements. The binding energy scale was then corrected with the $\mathrm{C}-\mathrm{C}$ bound of the $\mathrm{C} 1 \mathrm{~s}$ photoelectron peak located at $284.6 \mathrm{eV}$. Peak fitting of the $\mathrm{Cu} 2 \mathrm{p} 3 / 2$ photoelectron peak, along with the kinetic energy of the $\mathrm{Cu} \mathrm{L}_{3} \mathrm{M}_{4,5} \mathrm{M}_{4,5}$ peak, were used to evaluate the chemical state of copper. 
Optical characterization

Optical characterization was carried out on crystals in the solid state, and in dilute suspensions. For measurements in suspension, the crystals were crushed and suspended in ethanol/water solvent mixtures with varying ratios of water. For solid measurements, crystals were grown on glass pieces placed inside the reaction vials, and the optical properties of the films measured. PXRD patterns were measured after all measurements to ensure stability of the material. Similarity between the emission spectra of $\mathrm{Cu}_{2} \mathbf{L}_{3}$ films grown on glass substrate and $\mathbf{C u}_{2} \mathbf{L}_{3}$ crystals dispersed in dilute suspensions can be seen in fig. S1 below. Stability of $\mathbf{C u}_{2} \mathbf{L}_{3}$ crystals after suspension in aqueous solution is demonstrated in Fig. $2 \mathrm{f}$ in the main manuscript.

a

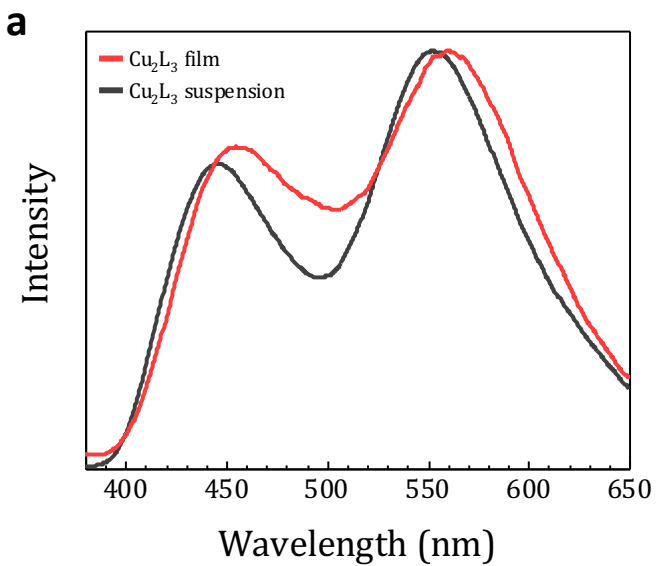

b

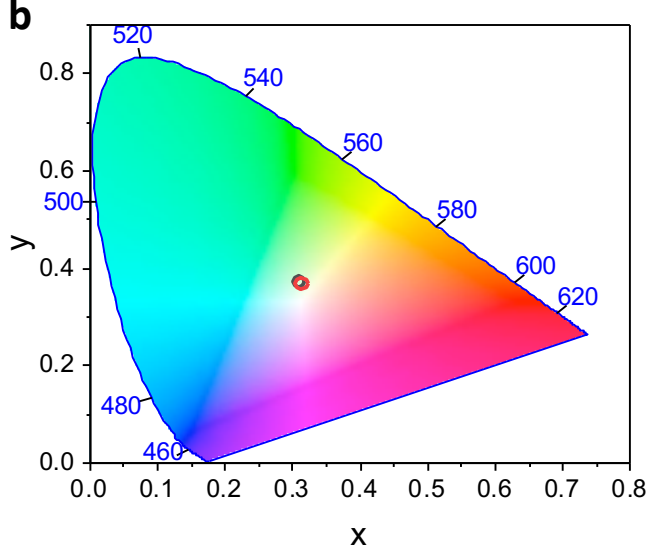

Fig. S1.

a Photoluminescence emission spectra and $\mathbf{b}$ corresponding CIE coordinates of as-synthesized $\mathrm{Cu}_{2} \mathbf{L}_{3}$ crystals, formed on a glass substrate (in red), and suspended in a $25 \% \mathrm{H}_{2} \mathrm{O}$ solution (in black). It should be noted that the emission intensity of $\mathrm{Cu}_{2} \mathrm{~L}_{3}$ in the solid film form is lower due to aggregation quenching $(16,17)$. Emission intensity of the film is normalized to that of the suspension for a comparison of the peak positions.

UV-visible absorption and diffuse reflectance spectra were recorded on a PerkinElmer LAMBDA 1050 spectrometer equipped with a praying mantis. Steady state photoluminescence spectra and absolute quantum yields were measured using a Horiba Fluorolog-3 equipped with an integrating sphere. Reported quantum yield value is an average of five independent measurements. 


\section{Device Fabrication}

$5 \mathrm{mg}$ of $\mathrm{ZrLH}_{2}$ was dissolved in $1 \mathrm{~mL}$ of methanol, and then mixed in a 1:5 volume ratio with a $30 \mathrm{mg} / \mathrm{mL}$ methanol solution of polyvinylpyrrolidone. The solution was drop-cast onto cleaned indium-tin-oxide-(ITO)-coated glass substrates and left to dry in open air to form the active layer. A gallium-indium (GaIn) eutectic paste was applied to the dried active layer through a mask to form the cathode. Copper wire was contacted to the GaIn eutectic and sealed with epoxy or Kapton tape. An applied voltage of $5 \mathrm{~V}$ across the simple device gives rise to cold white light emission shown in Fig. 4d of the main manuscript.

\section{Density Functional Theory calculations}

Absorption spectra calculations were done with Kohn-Sham DFT(45) and linear response Time-Dependent DFT (TDDFT)(46) using the PBE0(20) functional and 6-311 $\mathrm{g}(\mathrm{d})$ basis set $(48,49)$ including implicit solvent (ethanol) by means of the $\operatorname{CPCM}(50,51)$ method as implemented in Gaussian 09 code(52), for the isolated ligand and for the $\mathrm{Cu}_{2} \mathrm{~L}_{3}$ complex being all 6'-OH groups protonated.

\section{Molecular simulations}

For all our simulations we used the DFT-optimized unit cell. Van der Waals interactions between the framework atoms were modelled using Universal Force Field(53) with the tail corrections (54). Charges on the framework atoms were calculated with DDEC method using the electronic density calculated from geometrically optimized structure. Lennard-Jones parameters for water and ethanol molecules were taken from TIP4P2005(55) and TraPPE(56), respectively. Pairwise interactions were calculated using Lorentz-Barthelot mixing rules. The interactions between an atom and the atoms beyond the cut-off $12.5 \AA$ were computed using a tail correction.

The Grand Canonical Monte Carlo (GCMC) simulations were carried out at $298.15 \mathrm{~K}$ and 0.02 bar. We utilized 500,000 equilibration cycles and at least 140,000 production cycles with combination of insertion/deletion, reinsertion, rotation, and translation moves. To increase the efficiency of the simulations, identity change moves were also used. One cycle consists of $\max (20, N)$ steps where $\mathrm{N}$ is the number of adsorbate molecule in the system. In addition to performing a single component simulation for water adsorption, we also considered binary mixture simulations due to the competitive adsorption effect. Binary mixture simulations were carried out for the feed mixture with the compositions of 50:50 and 25:75 (water: ethanol).

NVT Monte Carlo simulations were performed by starting from the last snapshot of the equilibrated GCMC simulation corresponding to the composition of interest. For the bulk composition of 25:75, this corresponds to 20 ethanol and 39 water molecules in the pores of the $3 \times 3 \times 2$ supercell, and for the 50:50 bulk composition, 14 ethanol and 67 water molecules. For the single adsorption of water, 122 molecules were loaded into the supercell. All of these loadings were achieved by inserting the molecules into the positions we took from the last snapshot of the GCMC simulations. Since we started from already equilibrated system, we utilized 300,000 production cycles with combination of reinsertion, rotation, and translation moves. One cycle consists of $\max (20, \mathrm{~N})$ steps where $\mathrm{N}$ is the number of adsorbate molecule in the system. All Monte Carlo simulations were performed on RASPA software package(57). 
Density plots and radial distribution functions

Cartesian coordinates of the oxygen atoms in the adsorbate molecules (water and ethanol) were taken from the snapshots that were stored during the simulations. The positions of the atoms were binned to a 3-D grid by counting the number of times that a grid point has been visited during the simulation. This grid data was used to calculate free energies from the Boltzmann distribution. These data were used to create the free energy grids shown in Fig. 3a$\mathrm{f}$, where the blue and pink areas are the iso-surfaces corresponding to an $80 \%$ probability to find the oxygen of water and ethanol inside this surface. To provide a more detailed picture of the water adsorption, we defined two principal adsorption sites and emphasized the corresponding minimum energy basins with different colors (black: site 1; green: site 2). Then, we calculated the probability of having a water molecule around the two adsorption sites for each composition, see fig S12.

To further quantify the effect of ethanol on the probability to find a water molecule next to the 6' oxygen of the luciferin that is in a protonated $\left(6^{\prime}-\mathrm{OH}\right)$ or non-protonated (6'-O-), see, we computed the radial distribution function of 6'-O with the oxygen of the water (fig. S13).

\section{Molecular model for luciferin@luciferase}

To quantify the similarity between our compound and the luciferin molecule in the protein, we performed similarity analyses between the structure of our compound and the $\mathrm{OxyLH}_{2}$ molecule embedded in the protein scaffold (PDB 2D1T).

To visualize the interface of $\mathbf{C u}_{\mathbf{2}} \mathbf{L}_{\mathbf{3}}$ with the environment shown in Fig. $3 \mathrm{~g}$-h, we created energy surfaces using the iRASPA program(57) (using the Ow parameters of the TIP5P-Ew model as a probe molecule for water at $298 \mathrm{~K}$ and the default force field of iRASPA, for the calculation of the adsorption surface (blue) of the molecule in the protein pocket we used the same parameters). 


\section{Supplementary Discussion}

\section{$\underline{\mathrm{ZrLH}_{2}} \underline{\text { structural details }}$}

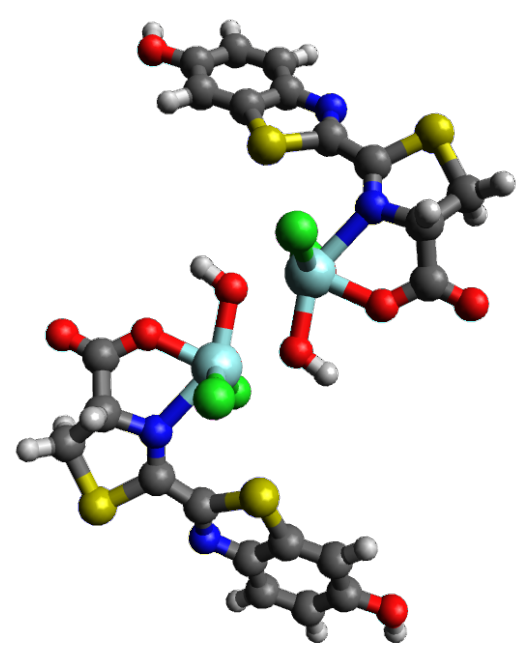

Fig. S2.

Structure of $\mathrm{Zr}_{2} \mathrm{LH}_{2}$ metal complex. OH-bridged dinuclear $\mathrm{Zr}$ complex with uncoordinated color-tuning $6^{\prime}-\mathrm{OH}$ groups. Atom color scheme: $\mathrm{C}=$ grey, $\mathrm{H}=$ white, $\mathrm{O}=$ red, $\mathrm{N}=$ blue, $\mathrm{S}=$ yellow, $\mathrm{Cl}=$ green, $\mathrm{Zr}$ $=$ cyan

To solve the structure of $\mathrm{ZrLH}_{2}$, we used a non-negative matrix factorization technique, related to the one described in(31) and implemented in [cheminfo ELN](http://cheminfo.github.io)(32), to deconvolve the mass spectrum. For this, we perform a peak picking (centroid) of the mass spectrum, generate all the theoretical isotopic distribution of all entities to look for, align the theoretical and experimental peaks and calculate a nonnegative matrix factorization to obtain the weights for the different entities. We enumerated theoretical isotope distributions for:

- deprotonated firefly luciferin ligand (in the range 0 to 3 )

- chloride (in the range 0 to 4 )

- $\mathrm{Zr}(\mathrm{IV})$ (in the range 0 to 3 )

- hydroxy (in the range 0 to 2 )

- methyl ester of the luciferin ligand (in the range 0 to 1 ) 
Fig. S3.

Mass spectrum of $\mathrm{Zr}-\mathrm{LH}_{2}$ reaction product

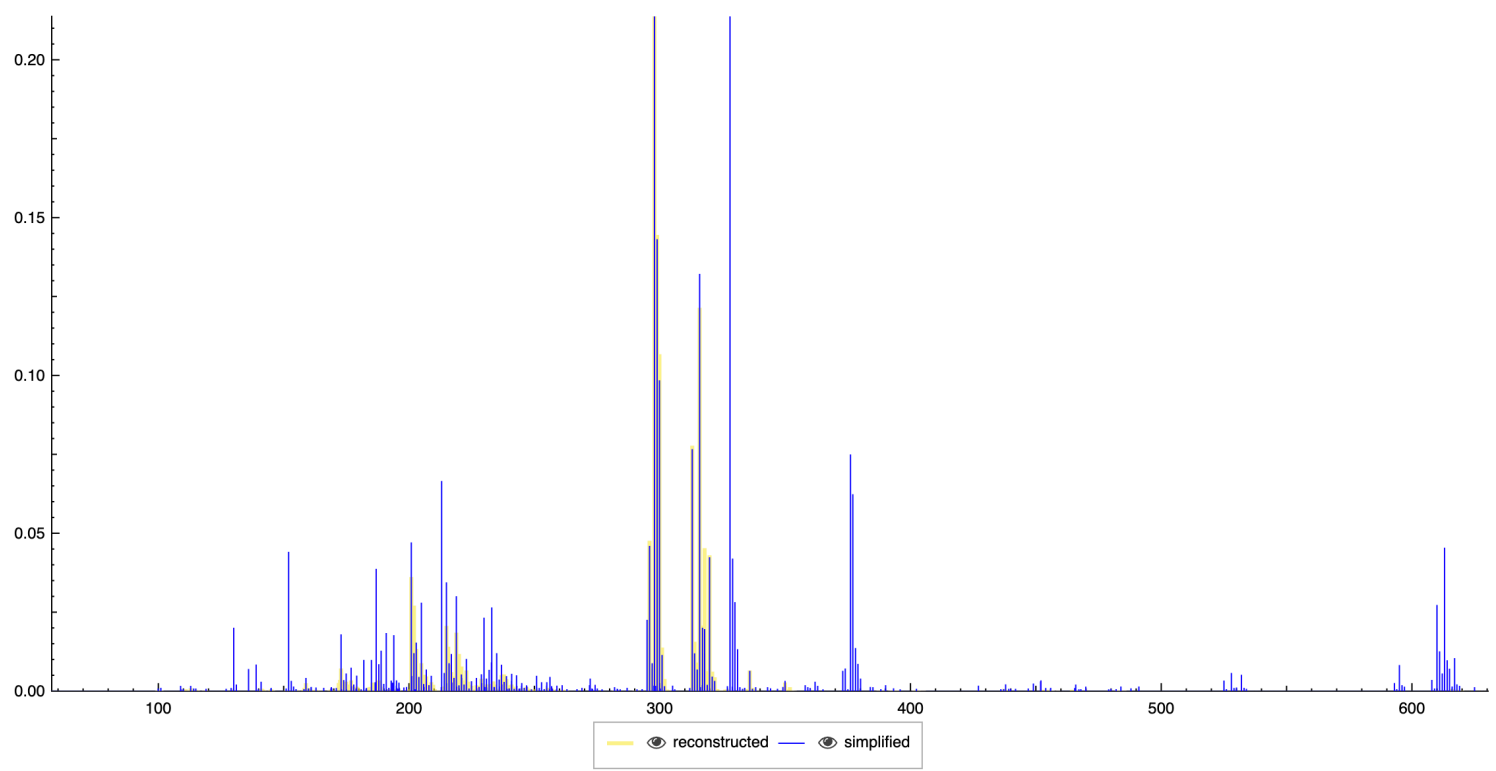

We considered the following ionizations: $\mathrm{H}^{+}, \mathrm{Na}^{+}, \mathrm{NH}_{4}^{+}$. The mass spectrum is dominated by the ammonium adduct of the ligand at $\mathrm{m} / \mathrm{z}=298$ and we also observe peaks of the methyl ester, such as the $[\mathrm{M}+\mathrm{H}]+$ at $\mathrm{m} / \mathrm{z}=295$. Moreover, many of the most relevant fragments from the reconstructed spectrum lead us to the working hypothesis of a dinuclear Zr complex:

- $\left[\mathrm{Zr}_{2} \mathrm{~L}(\mathrm{OH})_{2} \mathrm{Cl}_{3}{ }^{2+}+\mathrm{NH}_{4}{ }^{+}\right]$at $\mathrm{m} / \mathrm{z}=204.9$

- $\quad\left[\mathrm{Zr}_{2} \mathrm{~L}(\mathrm{OH})_{2} \mathrm{Cl}_{2}{ }^{4+}+\mathrm{NH}_{4}{ }^{+}\right]$at $\mathrm{m} / \mathrm{z}=112.5527$

- $\left[\mathrm{Zr}_{2} \mathrm{~L}_{2} \mathrm{Cl}_{3}{ }^{3+}+\mathrm{Na}^{+}\right]$at $\mathrm{m} / \mathrm{z}=215.9169$

- $\left[\mathrm{Zr}_{2} \mathrm{~L}_{2}(\mathrm{OH})_{2} \mathrm{Cl}^{3+}+\mathrm{Na}^{+}\right]$at $\mathrm{m} / \mathrm{z}=206.9338$

- $\left[\mathrm{Zr}_{2}(\mathrm{LH})_{2}(\mathrm{OH}) \mathrm{Cl}_{3}{ }^{4+}+\mathrm{H}^{+}\right]$at $\mathrm{m} / \mathrm{z}=172.1407$

- $\left[\mathrm{Zr}_{2} \mathrm{Cl}_{2}(\mathrm{OH}) \mathrm{L}(\mathrm{LH})^{4+}\right]$ at $\mathrm{m} / \mathrm{z}=205.9299$

- $\left[\mathrm{Zr}_{2}(\mathrm{LH}) \mathrm{LCl}_{4}(\mathrm{OH})_{2}{ }^{2+}+\mathrm{NH}_{4}{ }^{+}\right]$at $\mathrm{m} / \mathrm{z}=216.9043$

- $\left[\mathrm{Zr}_{2}\left(\mathrm{LH}_{2}\right) \mathrm{Cl}_{3}(\mathrm{OH})^{4+}+\mathrm{NH}_{4}^{+}\right]$at $\mathrm{m} / \mathrm{z}=214.9240$

- $\left[\mathrm{ZrL}(\mathrm{OH})_{2} \mathrm{Cl}+\mathrm{NH}_{4}{ }^{+}\right]$at $\mathrm{m} / \mathrm{z}=454.8948$

- $\left[\mathrm{ZrLCl}(\mathrm{OH})^{+}+\mathrm{NH}_{4}^{+}\right]$at $\mathrm{m} / \mathrm{z}=218.9458$

- $\left[\mathrm{ZrCl}_{2}(\mathrm{OH})_{2}(\mathrm{LH})^{+}+\mathrm{NH}_{4}{ }^{+}\right]$at $\mathrm{m} / \mathrm{z}=236.9341$ 


\section{$\underline{\mathrm{Cu}_{2}} \underline{\mathrm{L}}_{3} \underline{\text { crystal }} \underline{\text { structure description }}$}

During the synthesis, the $\mathrm{LH}_{2}$ precursor partially reduces some of the $\mathrm{Cu}^{\mathrm{II}}$ to $\mathrm{Cu}^{\mathrm{I}}$, while simultaneously being oxidized to its planar aromatic 2-(6'-hydroxy-2'-benzothiazolyl)thiazole-4-carboxylic acid (dehydroluciferin, L) form (Fig. 1a). The oxidation of $\mathrm{LH}_{2}$ to form $\mathrm{L}$ removes the chirality of the ligand precursor. $\mathrm{Cu}_{2} \mathrm{~L}_{3}$ thus crystallizes in the triclinic centrosymmetric space group $\mathrm{P} \overline{\mathbf{1}}$ with one metal complex present in the asymmetric unit. Each metal complex of $\mathrm{Cu}_{2} \mathrm{~L}_{3}$ is composed of three $\mathrm{L}$ molecules acting as ligands linked by two $\mathrm{Cu}$ ions (fig. S4). Cul links L1 to L2 via coordination bonds to the L1 3N, L1 4-COO, $\mathrm{L} 23 \mathrm{~S}$, and $\mathrm{L} 23^{\prime} \mathrm{N}$. Bridging of L2 3S, and L2 3' $\mathrm{N}$ by Cu 2 fixes the $\mathrm{C} 2-\mathrm{C} 2$ ' bond, presumably contributing to the enhanced photoluminescence quantum yield of the $\mathrm{Cu}_{2} \mathrm{~L}_{3}$ complex with respect to the free ligand. Cu2 links L2 to L3 via the $3 \mathrm{~N}$ and 4-COO groups of both ligands. Both $\mathrm{Cu} 1$ and $\mathrm{Cu} 2$ display distorted tetrahedral coordination geometries, with $\mathrm{Cu} 1$ in the $1+$ oxidation state and $\mathrm{Cu} 2$ in the $2+$ oxidation state. Both $\mathrm{Cu}$ ions form coordinate bonds with the $\mathrm{N}$ atoms of all three thiazole rings, as well as with the $\mathrm{O}$ atoms of all the ligand terminal carboxylate groups. $\mathrm{Cu} 1$ additionally bridges the thiazole and benzothiazole fragments of the central ligand via the $\mathrm{S}$ and $\mathrm{N}$ atoms.

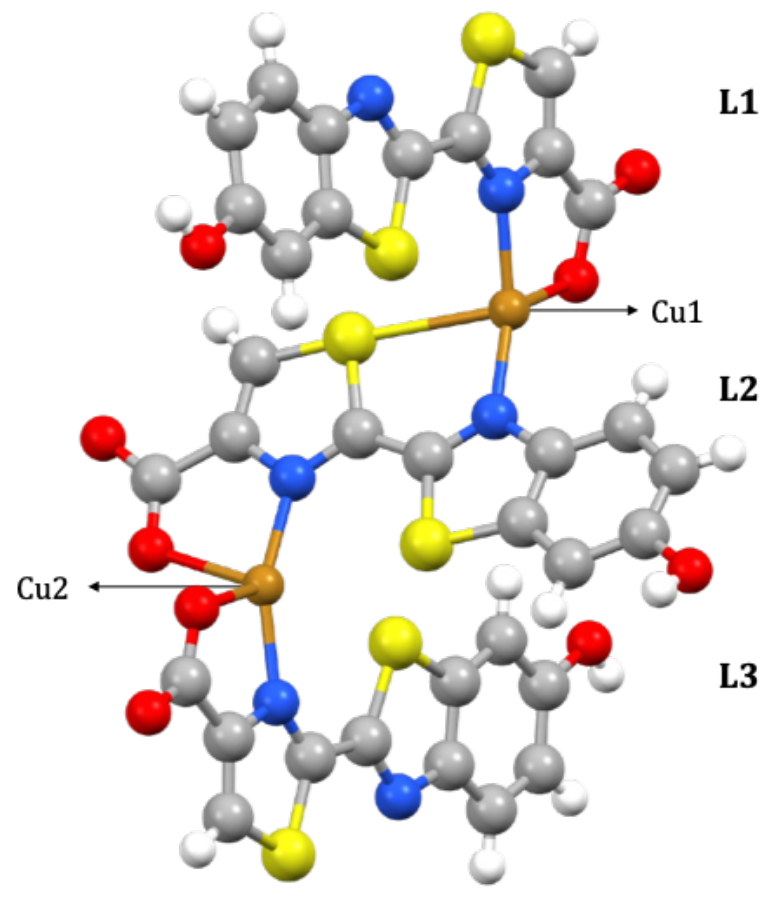

Fig. S4.

Asymmetric unit of the $\mathrm{Cu}_{2} \mathrm{~L}_{3}$ metal complex. Metal coordination bond lengths are indicated. The structure consists of two metal centers, $\mathrm{Cu} 1$ and $\mathrm{Cu} 2$, linking three ligands, L1, L2, and L3. $\mathrm{Cu} 1$ is in the $1+$ oxidation state, and $\mathrm{Cu} 2$, coordinated to the carboxylate $\mathrm{O}$ of $\mathrm{L} 2$ and $\mathrm{L} 3$, is in the $2+$ oxidation state. Atom color scheme: $\mathrm{C}=$ grey, $\mathrm{H}=$ white, $\mathrm{O}=\operatorname{red}, \mathrm{N}=$ blue, $\mathrm{S}=$ yellow, $\mathrm{Cu}=$ orange 
Despite the ligands of $\mathrm{Cu}_{2} \mathrm{~L}_{3}$ being planar, the coordination geometries of $\mathrm{Cu} 1$ and $\mathrm{Cu} 2$ impose a zigzag shape on the complex, with outer ligands rotated 90 degrees with respect to the central ligand. Ligands L1 and L3, positioned at the extremities of the metal complex (Fig. $\mathrm{S} 4)$, bind to the $\mathrm{Cu}$ centers through thiazolate $\mathrm{N}(\mathrm{N} 1-\mathrm{Cu} 1, \mathrm{~N} 5-\mathrm{Cu} 2)$ and carboxylate $\mathrm{O}(\mathrm{O} 1-$ $\mathrm{Cu} 1, \mathrm{O} 7-\mathrm{Cu} 2)$ atoms, whereas the L2 molecule positioned in the center of the metal complex, apart from the thiazolate $\mathrm{N}(\mathrm{N} 4-\mathrm{Cu} 2)$ and the carboxylate $\mathrm{O}(\mathrm{O} 4-\mathrm{Cu} 2)$, also uses the thiazolate $\mathrm{S}(\mathrm{S} 3-\mathrm{Cu} 1)$ and the benzothiazolate $\mathrm{N}(\mathrm{N} 3-\mathrm{Cu} 1)$ atoms to coordinate to the $\mathrm{Cu}$ centers. L2 is furthermore partially disordered as in the crystal structure a part of it assumes two discrete positions of unequal occupancy. The occupancies of the 2 components of the disorder were refined to approximately $1 / 3$ and $2 / 3$. Hydrogen bonds O9-H9 $\cdots \mathrm{O} 8$ (2.577(3) $\AA$ ) and $\mathrm{O} 3-\mathrm{H} 3 \cdots \mathrm{O} 2(2.608(3) \AA)$ join neighboring metal complexes of $\mathrm{Cu}_{2} \mathrm{~L}_{3}$ into chains

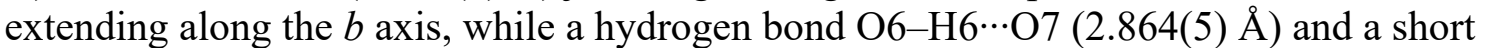

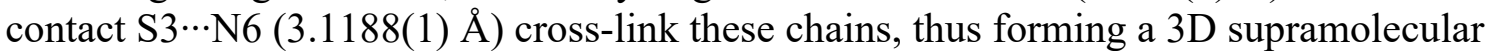
aggregate. Strong cohesion of this aggregate presumably contributes to its low solubility in water and common organic solvents.

To confirm the assignment of $\mathrm{Cu} 1$ and $\mathrm{Cu} 2$ oxidation states, the presence of $\mathrm{Cu}^{\mathrm{I}}$ and $\mathrm{Cu}^{\mathrm{II}}$ in the crystal structure was confirmed by X-ray photoelectron spectroscopy (XPS). XPS measurements confirmed the presence of $\mathrm{Cu}^{\mathrm{I}}$ and $\mathrm{Cu}^{\mathrm{II}}$ in a 1:1 ratio. Fitting of the $\mathrm{Cu} 2 \mathrm{p}_{3 / 2}$ line (fig. S5 a) shows two components with similar integrals, at binding energies of $932.5 \mathrm{eV}$ and $934.4 \mathrm{eV}$, which are assigned to $\mathrm{Cu}^{\mathrm{I}}$ and $\mathrm{Cu}^{\mathrm{II}}$ respectively. Since a binding energy of $\sim 933 \mathrm{eV}$ may typically correspond to either $\mathrm{Cu}^{\mathrm{I}}$ or $\mathrm{Cu}^{0}$, assignment of the $932.5 \mathrm{eV}$ peak to $\mathrm{Cu}^{\mathrm{I}}$ rather than $\mathrm{Cu}^{0}$ was further verified by Auger transitions (Fig. S5 b). Cu LMM transitions are similar $(\sim 916 \mathrm{eV})$ in $\mathrm{Cu}^{\mathrm{II}}$ and $\mathrm{Cu}^{\mathrm{I}}$, but higher in energy $(\sim 918 \mathrm{eV})$ in $\mathrm{Cu}^{0}$. The presence of a single peak at $916 \mathrm{eV}$ in the $\mathrm{Cu} \mathrm{LMM}$ line of $\mathrm{Cu}_{2} \mathrm{~L}_{3}$ confirms the absence of $\mathrm{Cu}^{0}$ in the complex. XPS data thus confirm that $\mathrm{Cu}_{2} \mathrm{~L}_{3}$ contains about $50 \% \mathrm{Cu}^{\mathrm{II}}$ and $50 \% \mathrm{Cu}^{\mathrm{I}}$.

a

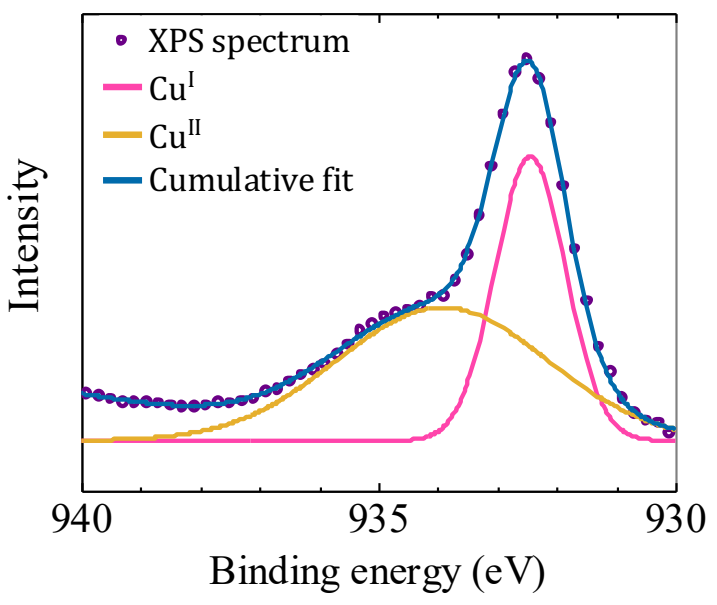

b

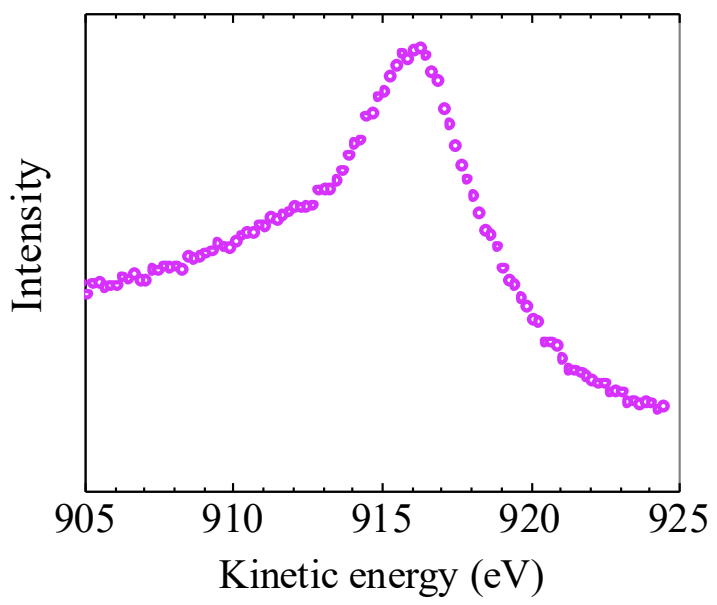

Fig. S5.

XPS and kinetic energy spectra a Cu $2 p$ XPS spectrum of as-synthesized $\mathrm{Cu}_{2} \mathrm{~L}_{3}$ b The presence of a single peak at $916 \mathrm{eV}$ in the kinetic energy spectrum of CuLMM transition in $\mathrm{Cu}_{2} \mathrm{~L}_{3}$ confirms the absence of $\mathrm{Cu}^{0}$ in the material. 

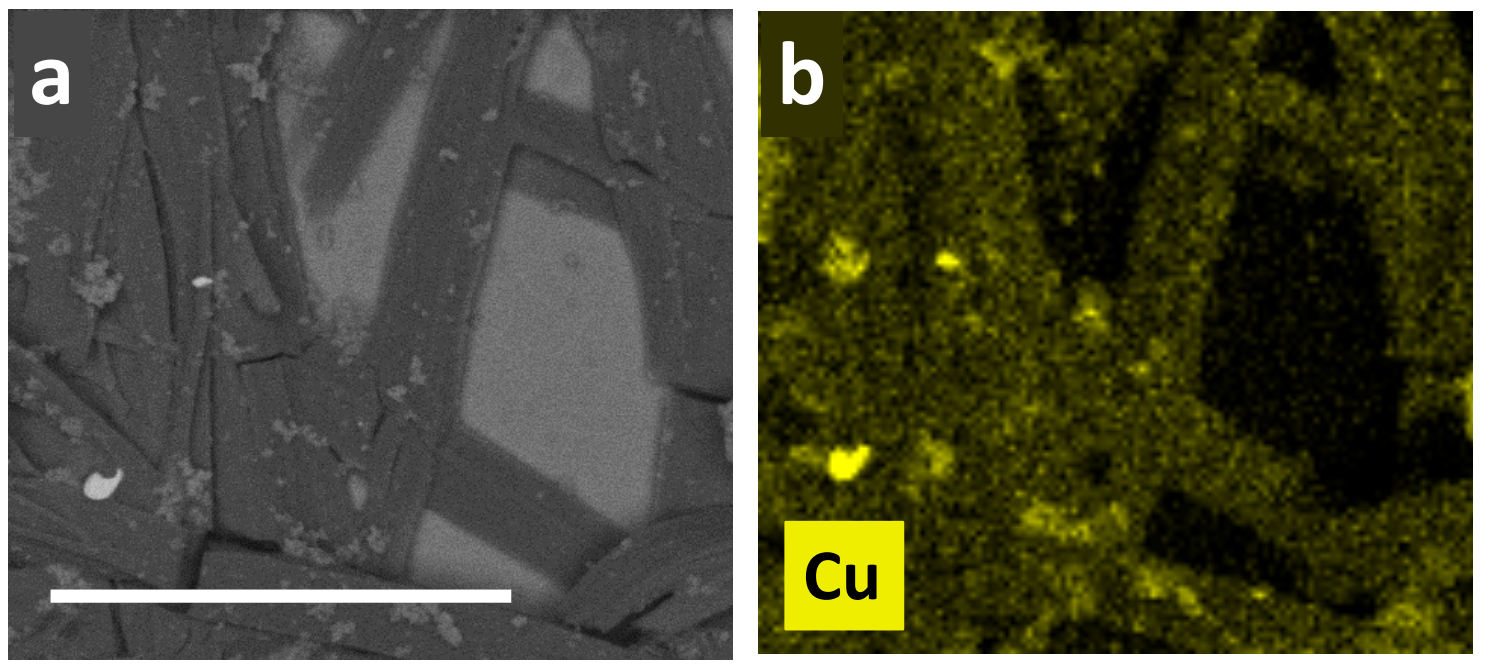

Fig. S6.

a SEM image, and $\mathbf{b}$ corresponding $\mathrm{Cu}$ EDX of as-synthesized Cu2L3. Scale bar corresponds to $10 \mu \mathrm{m}$

Scanning electron microscopy (SEM) and Energy Dispersive X-ray (EDX) images (Fig. $\mathrm{S} 6 \mathrm{a}, \mathrm{b})$ of $\mathrm{Cu}_{2} \mathrm{~L}_{3}$ show the flat, rectangular shape of the copper-rich crystals. 
Table S1.

Crystal data and structure refinement for $\mathrm{Cu}_{2} \mathrm{~L}_{3}$.

\begin{tabular}{|c|c|}
\hline Identification code & $\mathrm{Cu} 2 \mathrm{~L} 3$ \\
\hline Empirical formula & $\mathrm{C}_{33} \mathrm{H}_{16} \mathrm{Cu}_{2} \mathrm{~N}_{6} \mathrm{O}_{9} \mathrm{~S}_{6}$ \\
\hline Formula weight & 959.96 \\
\hline Temperature/K & 127.93 \\
\hline Crystal system & triclinic \\
\hline Space group & $P \overline{1}$ \\
\hline$a / \AA$ & $10.6952(5)$ \\
\hline$b / \AA$ & $13.6637(7)$ \\
\hline$c / \AA ̊$ & $15.4144(8)$ \\
\hline$\alpha /^{\circ}$ & $114.8850(10)$ \\
\hline$\beta /^{\circ}$ & $98.494(2)$ \\
\hline$\gamma /{ }^{\circ}$ & $100.936(2)$ \\
\hline Volume $/ \AA^{3}$ & $1939.77(17)$ \\
\hline$Z$ & 2 \\
\hline$\rho_{\text {calc }} \mathrm{g} / \mathrm{cm}^{3}$ & 1.644 \\
\hline$\mu / \mathrm{mm}^{-1}$ & 1.480 \\
\hline$F(000)$ & 964.0 \\
\hline Crystal size $/ \mathrm{mm}^{3}$ & $0.225 \times 0.05 \times 0.04$ \\
\hline Radiation & $\operatorname{MoK} \alpha(\lambda=0.71073)$ \\
\hline $2 \theta$ range for data collection $/{ }^{\circ}$ & 4.358 to 52.898 \\
\hline Index ranges & $-13 \leq h \leq 13,-17 \leq k \leq 17,-19 \leq l \leq 19$ \\
\hline Reflections collected & 57298 \\
\hline Independent reflections & $7962\left[R_{\text {int }}=0.0460, R_{\text {sigma }}=0.0331\right]$ \\
\hline Data/restraints/parameters & $7962 / 331 / 543$ \\
\hline Goodness-of-fit on $F^{2}$ & 1.069 \\
\hline Final $R$ indexes $[I \geq 2 \sigma(I)]$ & $R_{1}=0.0431, w R_{2}=0.0907$ \\
\hline Final $R$ indexes [all data] & $R_{1}=0.0567, w R_{2}=0.0949$ \\
\hline Largest diff. peak/hole / e $\AA^{-3}$ & $0.76 /-0.74$ \\
\hline
\end{tabular}


Optical properties of $\underline{\mathrm{Cu}_{2}} \underline{\underline{\mathrm{L}_{3}}}$

$\mathbf{C u}_{2} \mathbf{L}_{3}$ crystals are emissive, porous molecular crystals, which mimic bioluminescence color-tuning in response to changing chemical environment within the pores. $\mathbf{C u}_{2} \mathbf{L}_{3}$ crystals exhibit stable, tunable, and broad-spectrum emission. The optical properties of $\mathbf{C u}_{2} \mathbf{L}_{3}$ are ligand-based and therefore similar to those of the $\mathrm{LH}_{2}$ precursor. The neutral complex emits at $430 \mathrm{~nm}$, and deprotonation of the photoexcited $6^{\prime}-\mathrm{OH}$ groups by water molecules present in the pores of $\mathbf{C u}_{2} \mathbf{L}_{3}$ crystals results in a redshifted emission peak centered at $550 \mathrm{~nm}$ (Fig. 2c).

Dispersions of $C_{\mathbf{u}_{2}} \mathbf{L}_{3}$ in a range of non-aqueous solvents, including ethanol, dimethylformamide (DMF), N-methyl-2-pyrrolidone (NMP), and benzene, exhibit only the $430 \mathrm{~nm}$ phenol signature peak in their emission spectra, (Fig. S7), indicating full protonation of the benzothiazole terminals. In pure water and aqueous sodium hydroxide $(\mathrm{NaOH})$ and buffers of $\mathrm{pH} 9$ and 4, only the $550 \mathrm{~nm}$ phenolate emission is present, indicating complete deprotonation of the benzothiazole terminals (Fig. S7). Notably, the effect of $\mathrm{pH}$ on the protonation state of the phenol terminals is negligible compared to that of $\mathrm{H}_{2} \mathrm{O}$, due to the low $\mathrm{p} K_{\mathrm{a}}$ of these terminals in the excited state, as confirmed by dominance of the $6^{\prime}-\mathrm{O}^{-}$ characteristic peak at $\mathrm{pH} 4$.

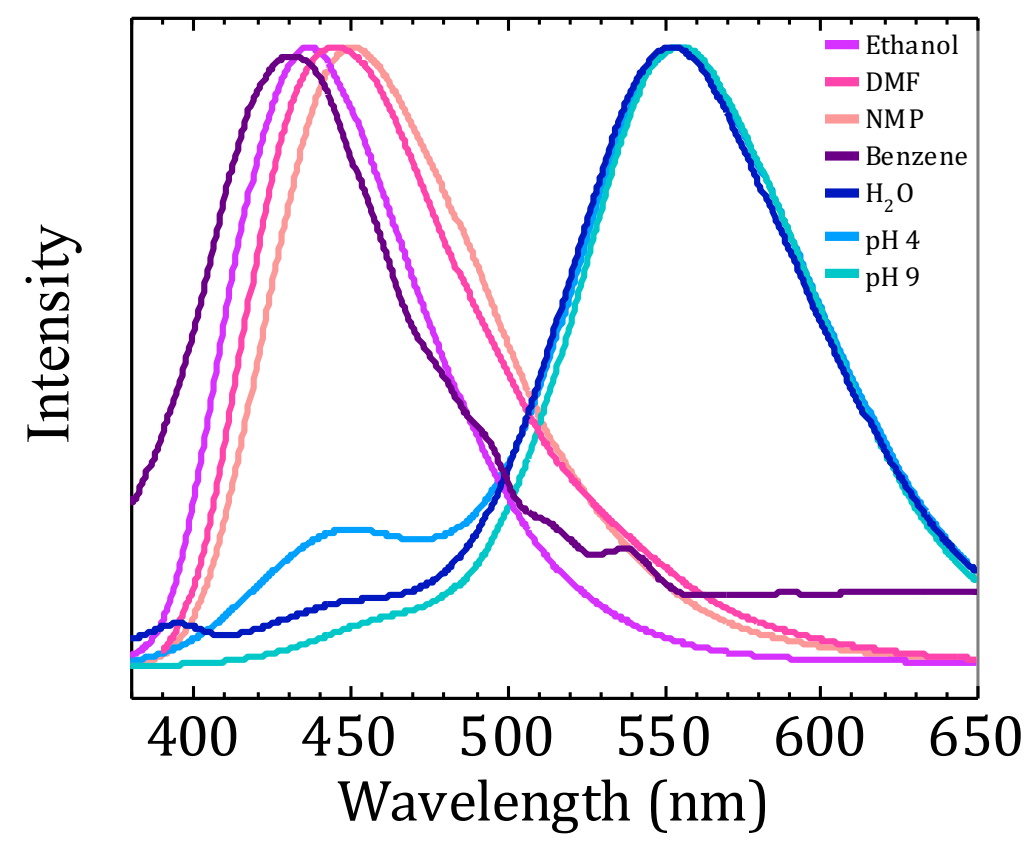

Fig. S7.

Photoluminescence emission spectra of $\mathbf{C} \mathbf{u}_{2} \mathbf{L}_{3}$ crystals dispersed in a range of non-aqueous (purple lines) and aqueous (blue lines) solvents 


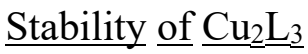

PXRD spectra of $C_{\mathbf{u}_{2}} \mathbf{L}_{3}$ crystals after being soaked in aqueous solution overnight, then centrifuged and dried (Fig. 2f) confirm that the insoluble complex is stable and retains its crystallinity after being dispersed in water-rich solvent mixtures.

Fourier Transform Infra-red (FTIR) spectra before and after soaked (fig. S8) further confirm the stability of the complex. The more pronounced phenol-OH band around $3200 \mathrm{~cm}^{-}$ ${ }^{1}$ in the FTIR of the soaked material suggests that water molecules in the solution approach the $-\mathrm{OH}$ groups of the complex. The fingerprint region of the spectra is the same before and after soaking, which confirms that the material remains stable.

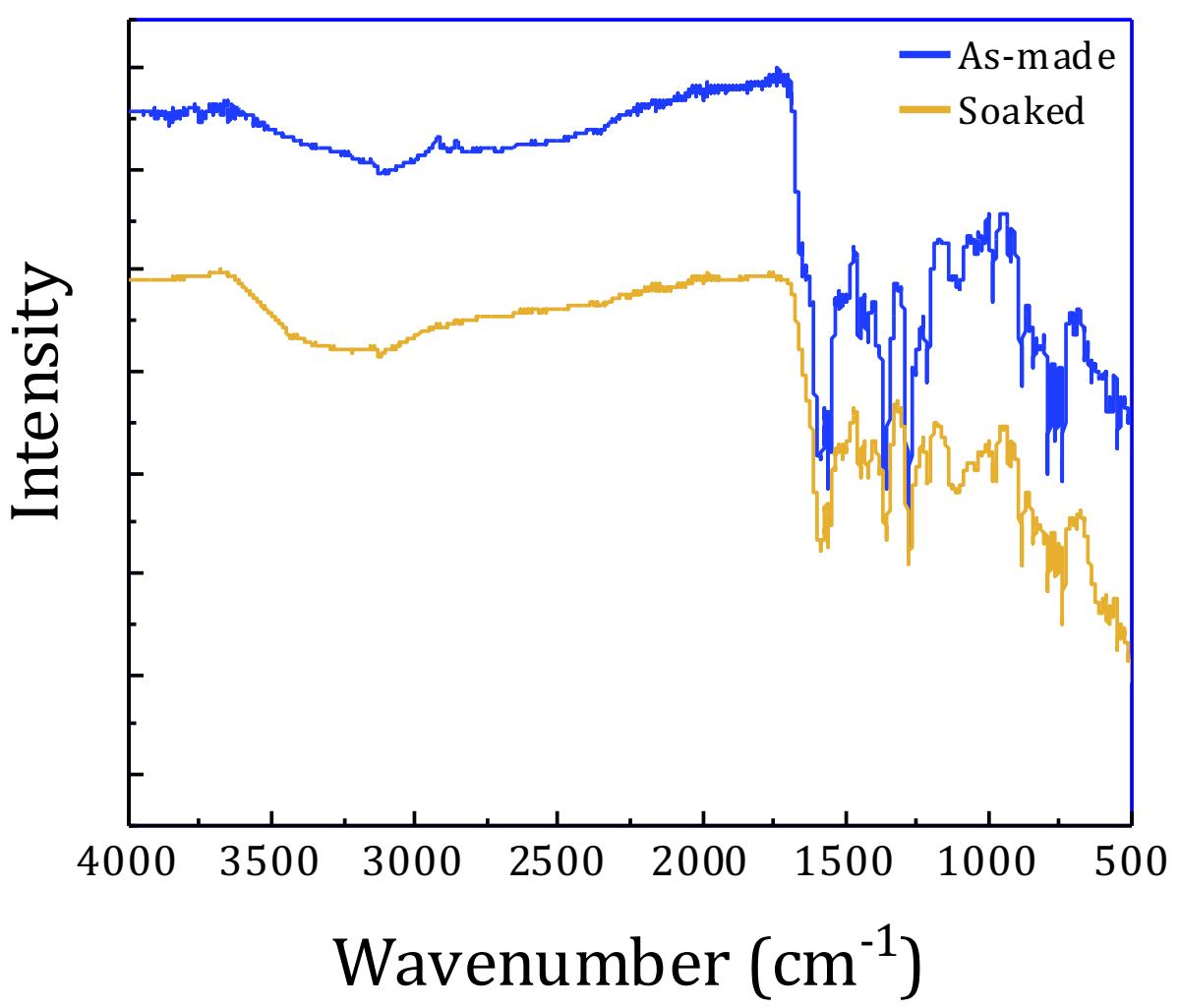

Fig. S8.

FTIR spectra of $\mathbf{C} \mathbf{u}_{2} \mathbf{L}_{3}$ crystals before (blue) and after (yellow) being dispersed in aqueous solution and soaked overnight. 
Density Functional Theory calculations

Absorption spectra calculations were done with Kohn-Sham DFT(18) and linear response Time-Dependent DFT (TDDFT)(46) using the PBE0(47) functional and 6-311g(d) basis set $(35,45)$ including implicit solvent (ethanol) by means of the CPCM method as implemented in Gaussian 09 code(52), for the isolated ligand and for the $\mathbf{C u}_{2} \mathbf{L}_{3}$ complex being all 6'-OH groups protonated. Analysis of the active excited states allowed determining that $S_{1}$ is the low-lying absorbing state of the ligand corresponding to the HOMO-LUMO excitation. The computed peak of $\mathbf{C u}_{2} \mathbf{L}_{3}$ complex is slightly red-shifted with respect to the isolated ligand in agreement with the experiments (fig. S9) and corresponds to the sum of the local excitations of the three L ligands (fig. S10). Low-lying charge transfer states involving transitions from the d-orbitals of $\mathrm{Cu}$ to the ligands are found with weak intensities at lower energies.
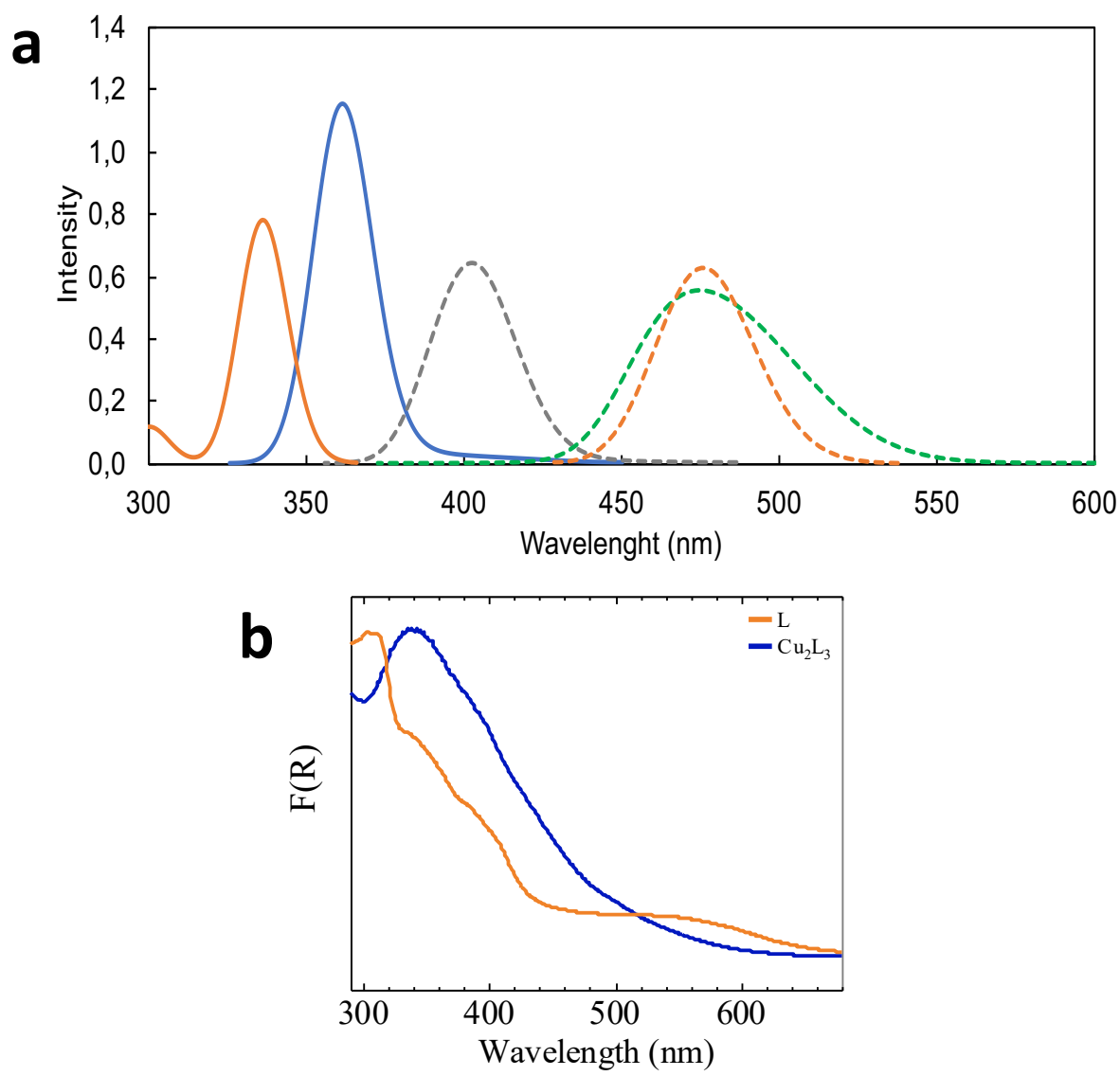

Fig. S9.

a Computed absorption (thin lines) and emission (dashed lines) spectra of L ligand (orange) and $\mathbf{C} \mathbf{u}_{2} \mathbf{L}_{3}$ complex (blue). Protonated (grey) and deprotonated (green) emission states $\left(\mathrm{O}^{-}\right)$of $\mathbf{C u}_{2} \mathbf{L}_{3}$ have been considered. A width of $0.3 \mathrm{eV}$ was used in the spectra, $\mathbf{b}$ Diffuse reflectance spectra of $\mathbf{L}$ and $\mathbf{C u}_{2} \mathbf{L}_{3}$ show a comparable redshift in the peak absorption of the ligand $\mathrm{L}$ in the free and complexed form. 


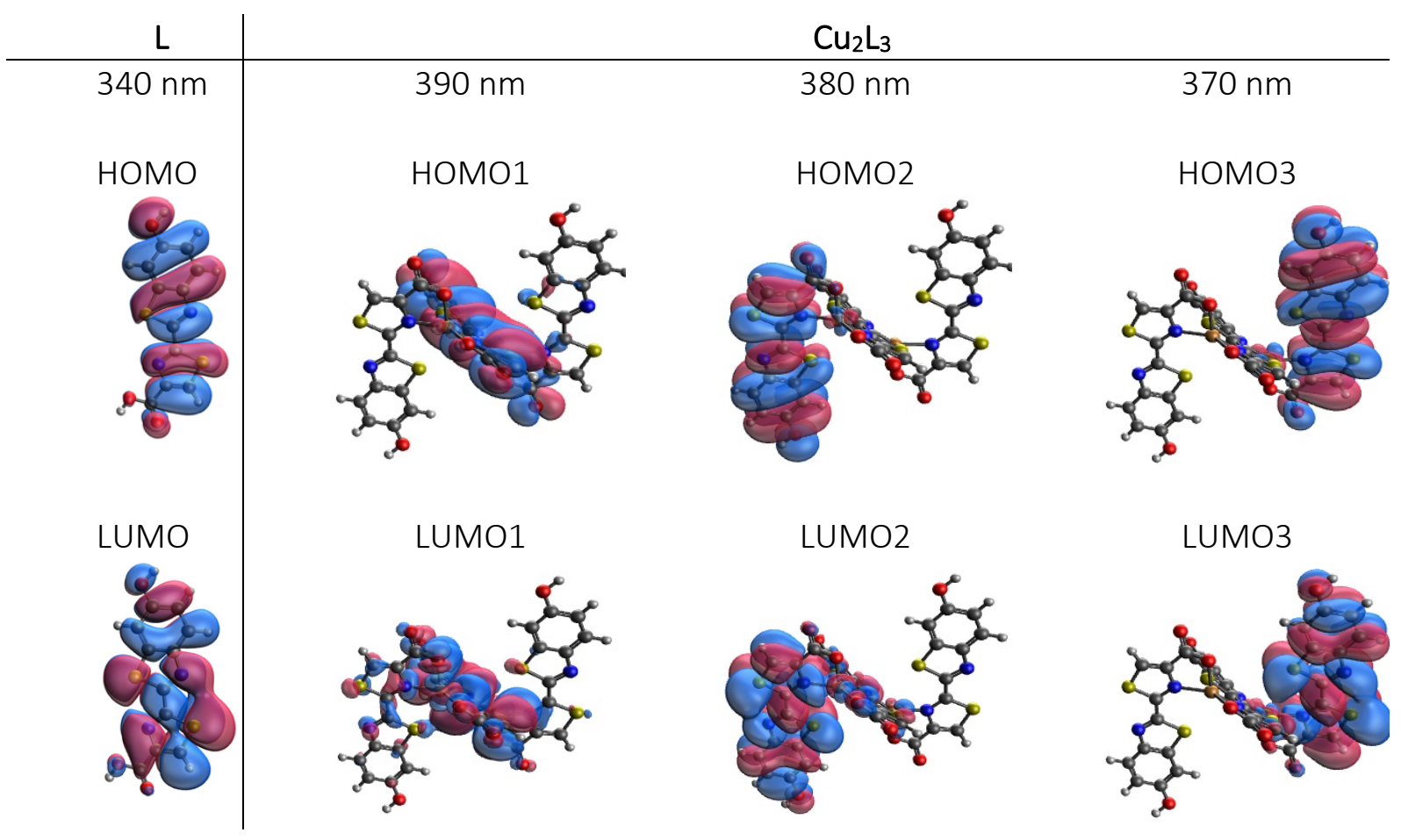

Fig. S10.

Molecular orbitals associated with the electronic transition corresponding to the absorption peak of $\mathbf{L}$ computed at $340 \mathrm{~nm}$, and with the three main excitations contributing to the absorption band of $\mathbf{C u}_{2} \mathbf{L}_{3}$ complex computed at 390, 380 and $370 \mathrm{~nm}$.

Optimization of $\mathrm{S}_{1}$ excited state of $\mathbf{L}$ ligand (in its deprotonated form) was done to obtain the simulated emission spectrum. Evaluation of the emission spectrum of $\mathbf{C u}_{2} \mathbf{L}_{3}$ complex was performed by means of substituting the three $\mathbf{L}$ ligands in the complex with its $\mathbf{S}_{1}$ optimized geometry. Both the protonated and deprotonated state of the $\mathrm{OH}$ groups of $\mathbf{L}$ were considered. 
The same methodology was applied to evaluate the emission properties of the Sesubstituted $\mathbf{C u}_{2} \mathbf{L}_{3}$ complex, and with an extended ligand that substitute the benzene ring by naphthalene (fig. S11). Comparison of the computed and experimental emission spectra of $\mathbf{C u}_{2} \mathbf{L}_{3}$ complex indicates that the emission energies are overestimated by $0.31 \mathrm{eV}$ in the calculations. Therefore, a shift of $0.31 \mathrm{eV}$ is applied to the computed emission spectra in order to predict the emission properties of the modified compounds in terms of CIE coordinates.

$\mathrm{Cu}_{2} \mathrm{~L}_{3}(\mathrm{Se}-\mathrm{L})$
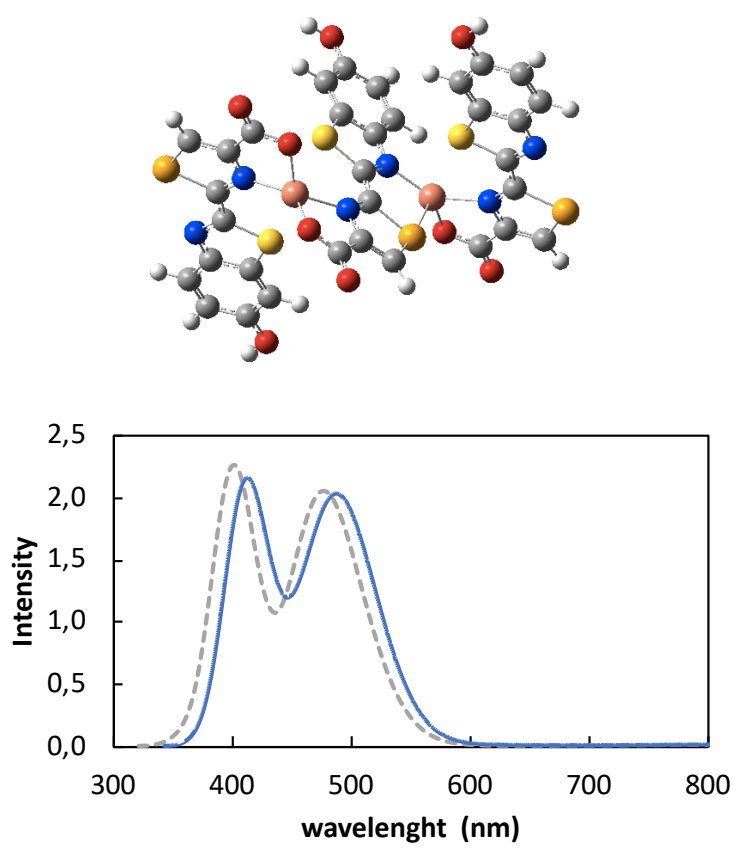

$\mathrm{Cu}_{2} \mathrm{~L}_{3}$ (naphthalane-L)
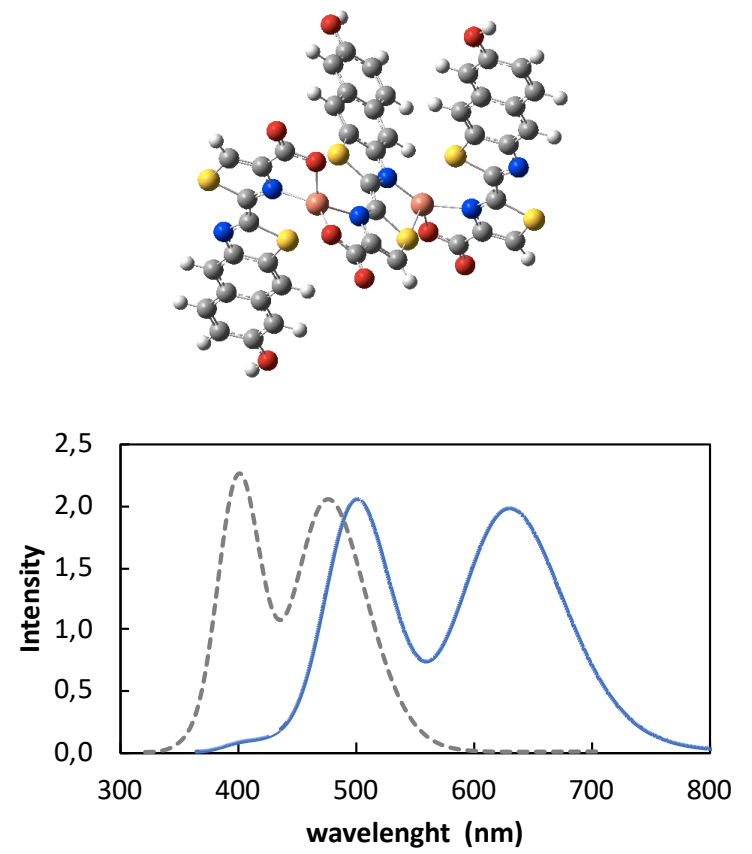

Fig. S11.

Structure and emission of predicted $\mathrm{Cu}_{2} \mathrm{~L}_{3}$-like complexes Computed geometry and emission spectra (blue lines) of $\mathrm{Cu}_{2} \mathrm{~L}_{3}$ complex with Se-substituted $\mathrm{L}$ ligands (left) and naphthalene $\mathrm{L}$ (right). The computed emission spectra of $\mathrm{Cu}_{2} \mathrm{~L}_{3}$ is also given for comparison (grey dotted lines). Both protonated and deprotonated forms of 6'-OH are considered. A width of $0.3 \mathrm{eV}$ was used in the spectra representation. 


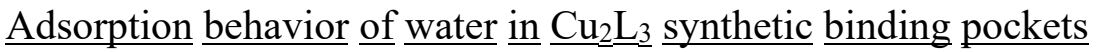

To obtain a qualitative molecular understanding of the behavior of water and ethanol inside the pores, we carried out molecular simulations. To determine the selective adsorption, we carried out grand-canonical Monte Carlo simulations and NVT Monte Carlo simulations.

Simulation results: Fig. 3 a-f and fig. S12 show that ethanol has a pronounced effect on the water molecules next to the 6'-O. If we increase the ethanol concentration, the probability of a water molecule next to the 6'-O site decreases. Fig. S13 shows that while the probability of having a water molecule next to adsorption site 1 decreases with the increasing ethanol composition in the mixture, exact opposite happens for the adsorption site 2 , which clearly supports the hypothesis that water molecules are pushed away from the adsorption site 1 in the presence of ethanol.

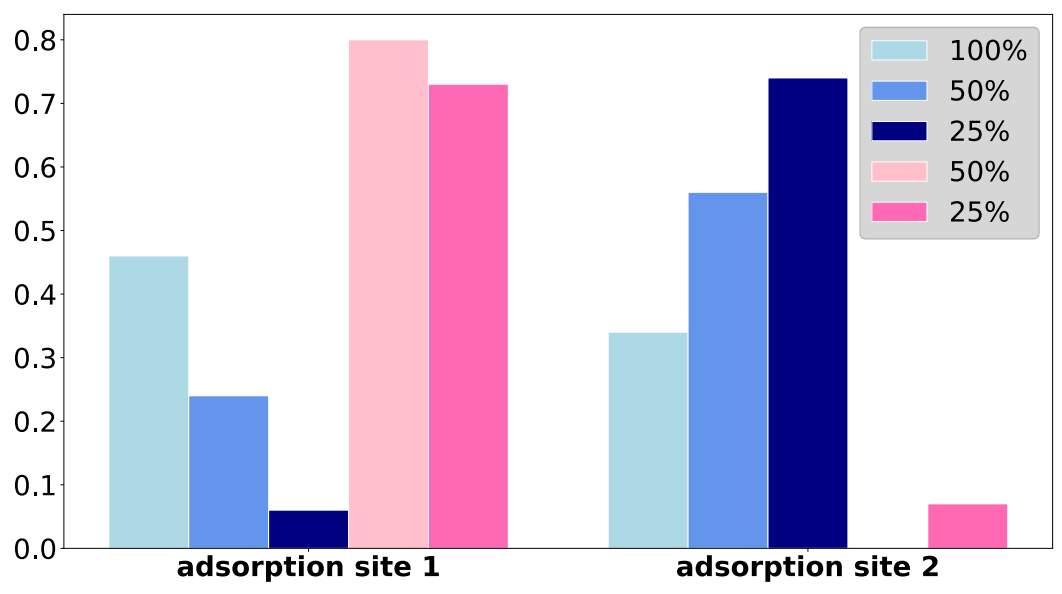

Fig. S12

Probability distribution of the oxygen atoms of water and ethanol molecules over the enumerated adsorption sites highlighted in fig. S13. Percentages in the legend represent water compositions. Blue and pink colors represent water and ethanol, respectively. 


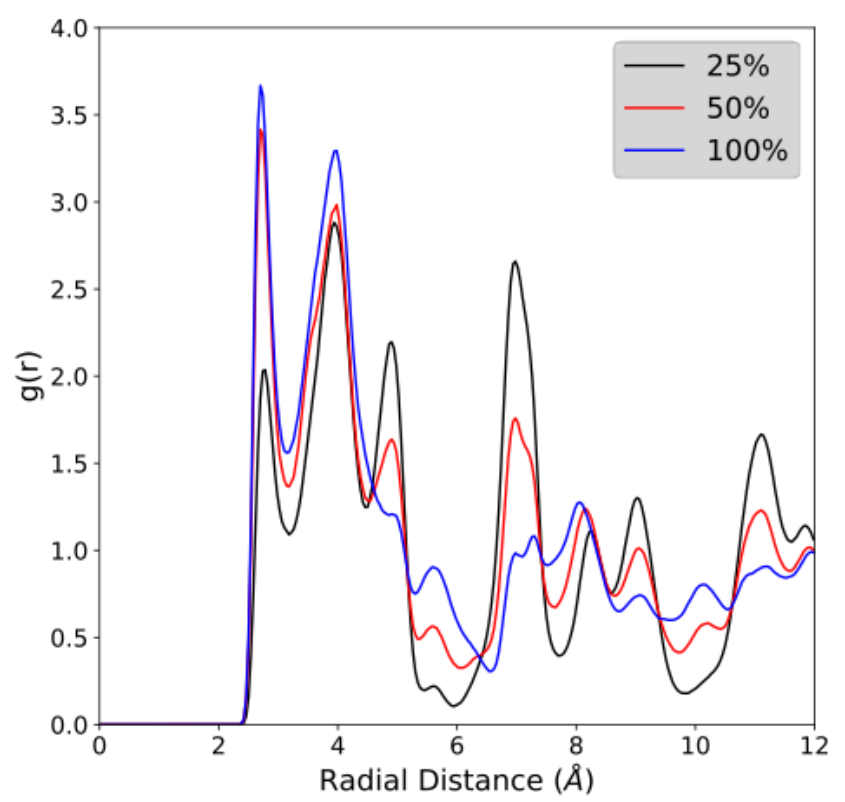

\section{Fig. S13}

Radial distribution plot of oxygen atoms in the water molecules from the oxygen positions of $\mathrm{OH}$ bonds that are expected to be deprotonated by water. 
Molecular model for luciferin@luciferase complexes

Luciferase/luciferin pairs are extensively investigated for use in bioimaging and analysis applications (58). Near- and far infra-red emitting systems in particular are of interest for in vivo bioimaging of hemoglobin-rich or high-density tissue such as bones. These applications drive the search for an understanding of bioluminescence color tuning mechanisms. Such an understanding may help guide the design of luciferase/luciferin variants that support high quantum yield bioluminescence well into the red.

Investigations of luciferase variants have unveiled a range of factors that may contribute to determining the bioluminescence emission color. The most commonly proposed factors include tautomerization of keto (red-emitting) and enol (green-emitting) forms of the thiazole fragment in luciferin(3), non-specific solvent interaction effects( 9 ), interactions between residues of the luciferase enzyme, and the confirmation of the active site $(8)$. While the community has yet to converge on a hypothesis that explains precisely how the emitted color is determined, recent studies have provided substantial mechanistic clues. For example, it was found that both green and red bioluminescence can be observed when the keto-like 5,5'dimethyl-oxyluciferin (dimethoxyluciferin), which cannot undergo tautomerism, is used as a substrate. Subsequent experimental and theoretical studies have served to dispute the impact of tautomerization within the luciferase binding site ${ }^{36}$. Residue interactions, conformation of the active site, and solvent interactions with the $6^{\prime}-\mathrm{OH}$ group can then be considered to play significant roles in determining whether the emission is green or red.

In-depth studies into the effects of site-directed mutations on a range of luciferase variants have shed light on the complex interplay between different factors present in bioluminescent systems. For example, even substitutions of randomly-distributed residues, distant from the luciferase binding site, have resulted in changes of the bioluminescence emission color, possibly due to effect of inter-residue interactions on the conformation and/or chemical environment of the binding site. Studies have shown that changes in the binding site conformation, whereby it takes on a more 'open' configuration, result in redshifting of the luminescence. This redshift has been attributed to the open-form microenvironment allowing excited oxyluciferin to rotate about its $\mathrm{C} 2-\mathrm{C} 2$ ' bond, thus lowering the energy of its radiative deexcitation. Several examples reported in the literature demonstrate that enlarging of the binding site or its surrounding cavity also result in redshifted emissions. Besides geometric relaxation, an alternative hypothesis to explain this tendency points to the effect of solvent interactions. Recent comprehensive structural studies of $\mathrm{pH}$-sensitive and $\mathrm{pH}$-insensitive luciferases suggest that increased accessibility of solvent molecules to the luciferase binding site result in red emissions. Interestingly, these studies also suggest that the 6 '-OH group of oxyluciferin lies close to the luciferase binding site region that is responsible for color determination. Within this region of the binding site, potential non-specific solvent effects that can result in redshifted emissions include changes in $\mathrm{pH}$, the concentration of metal ions, or the concentration water molecules. 


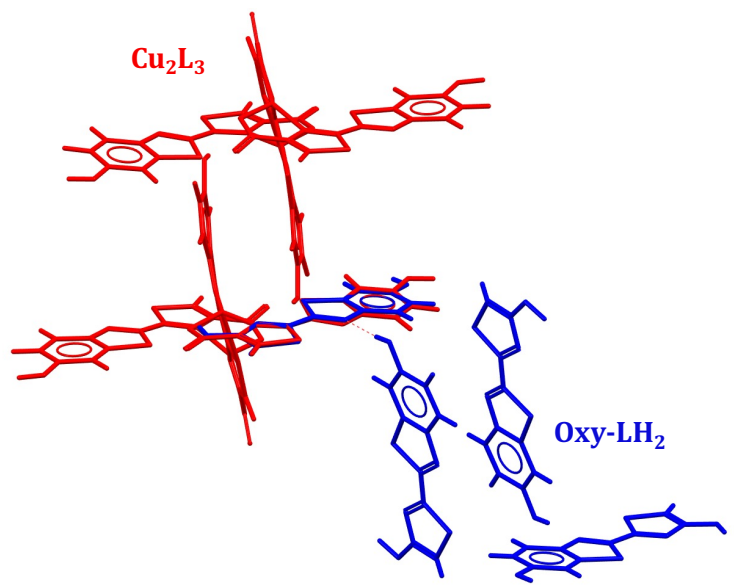

Fig. S14.

Crystal structure of the crystalized oxyluciferin illustrates the comparable intraligand interactions of the external ligands in $\mathrm{Cu}_{2} \mathrm{~L}_{3}$ 
As seen in Fig. S14, the geometry-optimized structure of $\mathrm{Cu}_{2} \mathrm{~L}_{3}$ (red) agrees almost perfectly (RMS $<0.067 \AA$ ) with the crystal structure of Oxy- $\mathrm{LH}_{2}$ reported by Naumov et $\mathrm{al}^{32}$ (blue). In the protein scaffold, the thiazole half of the benzothiazole ring can $\pi-\pi$ interact with the phenyl ring from Phe249, which is at a distance of $4.16 \AA$. In our compound, we find a stacking distance of approximately $3.7 \AA$, and similar to Naumov et al. we observe that the dimers are offset to each other. We also find a similar packing fraction of 0.12 as in the crystal of enol-Oxy- $\mathrm{L}_{2}(0.11)$.

Therefore, by proposing $C_{\mathbf{u}_{2}} \mathbf{L}_{3}$ and similar porous crystals as molecular models for bioluminescence color tuning effects, we are able to disentangle and separately investigate the different contributing factors that are currently under debate, and thus potentially contribute to the design of application-specific luciferases. In $\mathbf{C u}_{2} \mathbf{L}_{3}$, the thiazole rings are fixed in a planar aromatic ("enol-like") structure, and the $\mathrm{COOH}$ terminals, which take part in coordination, are unavailable to interact with the pore environment. Rigidity of the packed structure prevents rotation about the $\mathrm{C} 2-\mathrm{C} 2$ ' bond, eliminating any effects of geometry relaxation on the radiative deexcitation energy. Access of the $6^{\prime}-\mathrm{OH}$ groups of all three ligands in the asymmetric unit of $C_{\mathbf{u}_{2}} \mathbf{L}_{3}$ allows us to monitor the impact of the pore environment on the emission wavelength, in the absence of any other structural or chemical modifications.

Key structural similarities between the ligands in $\mathbf{C u}_{2} \mathbf{L}_{3}$, crystallized oxyluciferin, and AMP-complexed oxyluciferin in the Luciola cruciata binding site affirm the use of $\mathbf{C u}_{2} \mathbf{L}_{3}$ as a molecular model. Binding of the thiazole N3 to $\mathrm{Cu}$ in all three ligands of $\mathbf{C u}_{2} \mathbf{L}_{3}$ is comparable to $\mathrm{N} 3-\mathrm{O}$ binding to a 6 '-OH in crystallized oxyluciferin, and to a proximate water molecule in AMP-complexed luciferin of the L. cruciata species. N3-Cu bond lengths in $\mathbf{C u}_{2} \mathbf{L}_{3}$ range from $1.927 \AA$ to $1.983 \AA$, while in both, crystallized oxyluciferin and $\mathrm{LH}_{2} @$ L.cruciata the N$\mathrm{O}$ bonds range from $2.782 \AA$ to $2.878 \AA$. To quantify the similarity between our compound and the luciferin molecule in the protein, we performed similarity analyses between the structure of our compound and the $\mathrm{OxyLH}_{2}$ molecule embedded in the protein scaffold (PDB 2D1T). The geometry of our PBE optimized structure of $\mathbf{C u}_{2} \mathbf{L}_{3}$ (red) agrees perfectly (RMS < $0.067 \mathrm{~A}$ ) with the crystal structure of $\mathrm{OxyLH}_{2}$ reported by Naumov et al (blue). In the protein scaffold, the thiazole half of the benzothiazole ring can $\pi-\pi$ interact with the phenyl ring from Phe249, which is at a distance of 4.16 A. In our compound, we find a stacking distance of approximately $3.7 \mathrm{~A}$, and similar to Naumov et al. we observe that the dimers are offset to each other. We also find a similar packing fraction of 0.12 as in the crystal of enol-Oxy-OH2 (0.11).

To visualize the interface of $\mathbf{C} \mathbf{u}_{\mathbf{2}} \mathbf{L}_{\mathbf{3}}$ with the environment, we created energy surfaces using the iRASPA program (using the Ow parameters of the TIP5P-Ew model as a probe molecule for water at $298 \mathrm{~K}$ and the default force field of iRASPA, for the calculation of the adsorption surface (blue) of the molecule in the protein pocket we used the same parameters). It is clearly observable that, similar to the structure embedded in the protein, the phenolic $\mathrm{OH}$ can from all hydrogen bonding active functional groups most strongly interact with water.

We also find similar water coordination environments in our GCMC simulations. The maximum of the distribution of distances of the oxygen of the water molecule to oxygen the phenolic $\mathrm{OH}$ group is $3.3 \AA$ in our simulations, which is close to the distances of $2.73 \AA$ and $3.3 \AA$ that are found in the protein. 
Movie 1.

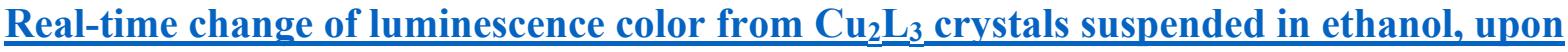
addition of water. 